\title{
MOLECULAR EVOLUTION OF GPCRS Kisspeptin/kisspeptin receptors
}

\author{
Jérémy Pasquier, Nédia Kamech, Anne-Gaëlle Lafont, Hubert Vaudry ${ }^{1}$, \\ Karine Rousseau and Sylvie Dufour
}

Laboratory of Biology of Aquatic Organisms and Ecosystems (BOREA), UMR CNRS 7208, IRD207, Université Pierre and Marie Curie - Paris 6, Muséum National d'Histoire Naturelle, 7 rue Cuvier, CP32, 75231 Paris Cedex 05, France ${ }^{1}$ Laboratory of Neuronal and Neuroendocrine Differentiation and Communication, INSERM U982, Institute for Research and Innovation in Biomedicine (IRIB), University of Rouen, 76821 Mont-Saint-Aignan, France

Correspondence should be addressed to S Dufour Email dufour@mnhn.fr

\begin{abstract}
Following the discovery of kisspeptin (Kiss) and its receptor (GPR54 or KissR) in mammals, phylogenetic studies revealed up to three Kiss and four KissR paralogous genes in other vertebrates. The multiplicity of Kiss and KissR types in vertebrates probably originated from the two rounds of whole-genome duplication (1R and $2 R$ ) that occurred in early vertebrates. This review examines compelling recent advances on molecular diversity and phylogenetic evolution of vertebrate Kiss and KissR. It also addresses, from an evolutionary point of view, the issues of the structure-activity relationships and interaction of Kiss with KissR and of their signaling pathways. Independent gene losses, during vertebrate evolution, have shaped the repertoire of Kiss and KissR in the extant vertebrate species. In particular, there is no conserved combination of a given Kiss type with a KissR type, across vertebrate evolution. The striking conservation of the biologically active ten-amino-acid C-terminal sequence of all vertebrate kisspeptins, probably allowed this evolutionary flexibility of Kiss/KissR pairs. KissR mutations, responsible for hypogonadotropic hypogonadism in humans, mostly occurred at highly conserved amino acid positions among vertebrate KissR. This further highlights the key role of these amino acids in KissR function. In contrast, less conserved KissR regions, notably in the intracellular C-terminal domain, may account for differential intracellular signaling pathways between vertebrate KissR. Cross talk between evolutionary and biomedical studies should contribute to further understanding of the Kiss/KissR structure-activity relationships and biological functions.
\end{abstract}

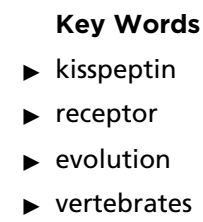

Journal of Molecular Endocrinology (2014) 52, T101-T117

\section{Introduction}

The kisspeptin system, composed of the ligand, kisspeptin (Kiss), and its receptor, kisspeptin receptor (KissR), has attracted the attention of most reproductive physiologists during the past 10 years. Even though the involvement of this neuroendocrine system in reproductive physiology was unveiled only in 2003, the first characterizations of its components date back to the 1990s. In 1996, Welch's group in Hershey (Pensylvania) isolated a novel cDNA from malignant melanoma cells that had lost the potential to metastasize after the introduction of human chromosome 6 (Lee et al. 1996). They designated this cDNA, Kiss1, in reference to Hershey's candy specialty, the

Published by Bioscientifica Ltd.

This paper is one of eight papers that form part of a thematic review section on the 
'Hershey Chocolate Kiss' and demonstrated that its transfection into C8161 melanoma cells suppressed metastasis. In 1999, a novel G protein-coupled receptor (GPCR), designated GPR54, was isolated in rat (Lee et al. 1999). The ortholog of GPR54 in human was cloned 2 years later and termed either AXOR12 (Muir et al. 2001) or hOT7T175 (Ohtaki et al. 2001). The same year, in order to identify the endogenous ligands of this orphan receptor, three research groups used heterologous cell models, i.e., CHO-K1 (Kotani et al. 2001), HEK293 (Muir et al. 2001) and B16-BL6 (Ohtaki et al. 2001), which they transfected with GPR54 (Kotani et al. 2001), AXOR12 (Muir et al. 2001), or hOT7T175 (Ohtaki et al. 2001). Three surrogate agonist peptides were thus isolated from the placenta extracts and named either kisspeptins (54, 14, and 13 amino acid peptides: (Kotani et al. 2001)) or metastin (54 amino acid peptide: (Ohtaki et al. 2001)).

In 2003, three groups revealed the link between hypogonadotropic hypogonadism $(\mathrm{HH})$ and mutation in GPR54, via reports of clinical cases (de Roux et al. 2003, Seminara et al. 2003) and knockout mouse models (Funes et al. 2003, Seminara et al. 2003). These studies showed that humans or mice in which GPR54 was mutated or lacking could not go through normal puberty, had small gonads, exhibited low plasma concentrations of sex steroids and gonadotropins, and were sterile. This major breakthrough in reproductive physiology was thereafter fully documented and the role of the kisspeptin system in the onset of puberty and reproduction was investigated, revealing a major stimulatory action on gonadotropin-releasing hormone (GNRH) neurons and possible direct effects on the secretion of luteinizing hormone (LH) and follicle-stimulating hormone (FSH) (for reviews see Roa et al. (2008), Pinilla et al. (2012) and Gopurappilly et al. (2013)). Recent studies involving knockdown experiments in fish have revealed the importance of the kisspeptin system in early development, especially in neurulation (Hodne et al. 2013).

Characterization of the kisspeptin system has been carried out in various vertebrate species, leading to the discovery of multiple genes encoding kisspeptins (from Kiss1 to Kiss3) (Biran et al. 2008, Felip et al. 2009, Kitahashi et al. 2009, Lee et al. 2009b, Pasquier et al. 2012b) as well as multiple genes encoding their receptors (from KissR1 to KissR4) (Biran et al. 2008, Felip et al. 2009, Lee et al. 2009b, Pasquier et al. 2012a). This diversity among kisspeptin systems led to studies on its evolutionary history (Akazome et al. 2010, Tsutsui et al. 2010, Pasquier et al. 2012a,b, Tena-Sempere et al. 2012). We review here recent advances on molecular diversity and phylogenetic evolution, structure-activity relationships, and signaling mechanisms of vertebrate kisspeptins and their receptors.

\section{Molecular diversity and phylogenetic evolution of kisspeptins in vertebrates}

Kisspeptins are members of the RFamide peptide family, named after the C-terminal motif, arginine (R) and phenylalanine (F) coupled to an amide function, shared by most peptides of this superfamily. The first characterized peptide of the RFamide family was isolated from the ganglia of the mollusc, Macrocallista nimbosa, and shown to act as a cardiac stimulator in this species (Price \& Greenberg $1977 a, b)$. Since this discovery, an increasing number of Rfamide-related peptides has been identified in other groups of metazoa including vertebrates. Besides kisspeptins, the RFamide superfamily also includes neuropeptides FF (NPFF), gonadotropin-inhibitory hormone (GNIH), prolactin-releasing peptides (PrRP), and 26RFamide peptides (Fukusumi et al. 2006, Tsutsui et al. 2010). Molecular phylogeny of the genes coding for these peptides allowed definition of the so-called 'RFamide' superfamily, even though some peptides do not end in 'RF', but for instance in 'RY' as exemplified by various vertebrate kisspeptins.

\section{Kiss gene, precursor structure and multiple mature peptide forms}

In mammals, the Kiss 1 gene is composed of three exons and two introns as shown in human (Cartwright \& Williams 2012), pig (Sus scrofa) (Tomikawa et al. 2010), and mouse (Mus musculus) (Tomikawa et al. 2012). The first exon only codes for the UTR, while the coding sequence (CDS) is split between exons 2 and 3 (Fig. 1). A similar gene structure of three exons and two introns has also been suggested for the zebrafish Kiss1 gene (Kitahashi et al. 2009). In other vertebrates, only the sequences corresponding to exons 2 and 3 have been described so far, similarly containing the Kiss CDS (for review see Tena-Sempere et al. (2012)).

After the discovery of the single Kiss1 gene in eutherian mammals, investigations of various vertebrates revealed the existence of up to three paralogous Kiss genes (Kiss1, Kiss2, and Kiss3 (Pasquier et al. 2012b)).

While no alternative splicing of the Kiss 1 gene has been identified, to our knowledge, in mammals, a recent study in a teleost species, the Senegalese sole (Solea senegalensis), has revealed the existence of two kiss2 transcript isoforms. These isoforms are generated by the retention of an intron between the two exons (Mechaly et al. 2011). The shortest isoform (Kiss2_v1) encodes a

Published by Bioscientifica Ltd 


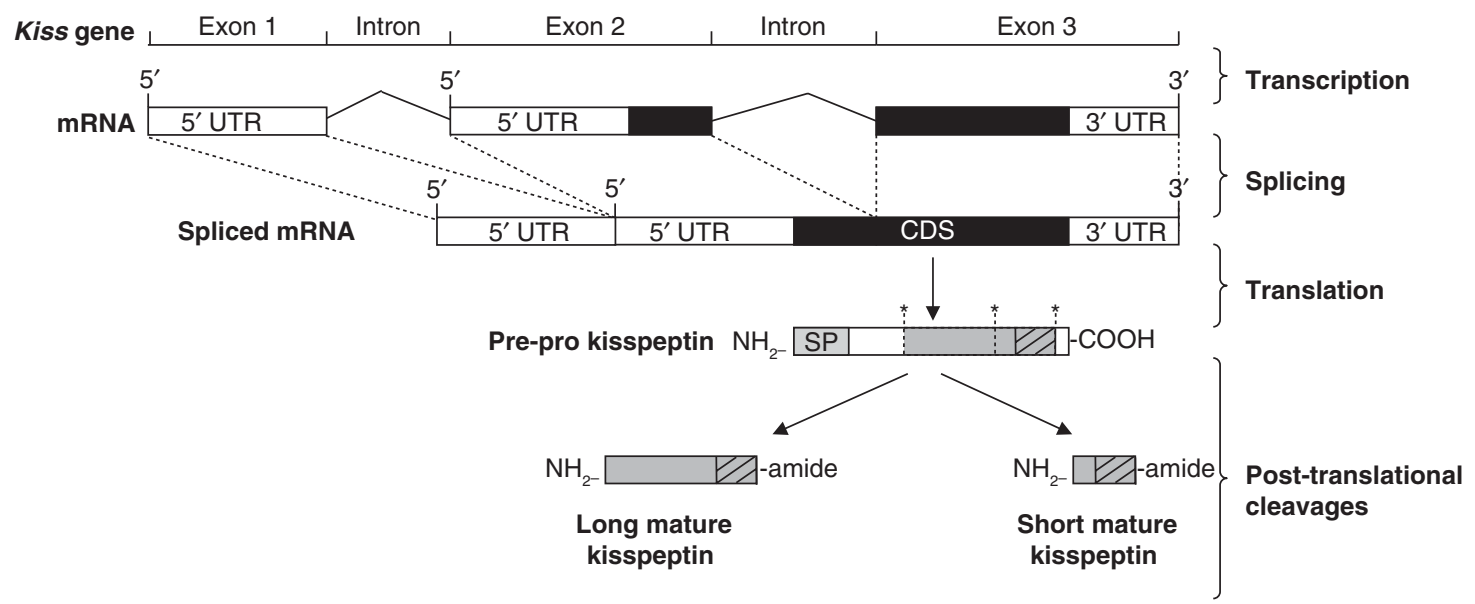

Figure 1

Kiss gene transcription, translation, and post-translational processing. CDS, coding sequence; SP, signal peptide. The minimal bioactive sequence, composed by ten amino acids, $\mathrm{Kp}(10)$, is represented by a hatched square.

classic Kiss2 precursor, while the longest one (Kiss2_v2) encodes a truncated and non-functional protein. To date, the Senegalese sole is the only species presenting such an alternative splicing process (Mechaly et al. 2011).

Each Kiss gene encodes a polypeptide precursor, which is secondarily processed to give size-variants of kisspeptins (Fig. 1). In humans, three mature peptides have been purified from placenta, i.e., kisspeptin1-54 (hKp1(54)), kisspeptin1-14 (hKp1(14)), and kisspeptin113 (hKp1(13)) (Kotani et al. 2001, Muir et al. 2001). To date, in other vertebrates, only a few mature forms of kisspeptin have been purified, i.e., Kp2(12) from Xenopus brain (Lee et al. 2009b), Kp2(12) from red-eared slider turtle brain, and Kp2(13) from Masu salmon brain (Osugi et al. 2013).

All these mature peptides encompass a C-terminal 10 -amino acid sequence, $(\operatorname{Kp}(10))$, which represents the minimal sequence for bioactivity (Fig. 2A; Kotani et al. 2001). This $\mathrm{Kp}(10)$ sequence is highly conserved among vertebrates (Fig. 2A). Positions 1 and 10 correspond to aromatic amino acids, Tyr or Phe, in all sequences. Positions 2, 4, 6, 7, 8, and 9 are fully conserved among vertebrates, except for mutations encountered in degenerating pseudogenes, such as the recently described mallard duck and crocodile Kp2-like genes (Fig. 2A). In all vertebrate species, the $\mathrm{Kp}(10)$ sequences are flanked at their C-terminal end by the sequence, 'G-Basic-Basic', or 'G-Basic-Stop', characteristic of the conserved proteolytic cleavage and $\alpha$-amidation sites of neuropeptides (Eipper et al. 1992). In contrast, the remaining part of the precursor sequence is highly variable among vertebrates and between paralogous kisspeptin precursors within a given species. This latter feature has been exploited to generate specific antibodies against distinct kisspeptin precursors (Servili et al. 2011).

\section{Diversity of Kiss genes in vertebrates}

Since the discovery of the first Kiss1 gene in humans, several Kiss genes have been identified in most vertebrate lineages including cyclostomes, chondrichthyes, teleosts, amphibians, and sauropsids (Lee et al. 2009b, Pasquier et al. 2012b, Tena-Sempere et al. 2012; Fig. 3). Phylogenetic and syntenic analyses (Lee et al. 2009b, Kim et al. 2012, Pasquier et al. $2012 a, b)$ revealed that the Kiss genes can be classified into three different clades (i.e., Kiss1, Kiss2, and Kiss3 clades, according to the recent nomenclature devised by Pasquier et al. (2012b)). In addition, syntenic analysis supports the potential existence of a fourth Kiss gene (Kiss4) in early vertebrates, although it has not yet been identified in any extant vertebrate species (Pasquier et al. 2012b).

Among extant sarcopterygians, various situations concerning the number of paralogous Kiss genes have been observed. In mammals, prototherians such as platypus (Ornithorhynchus anatinus) possess the Kiss1 and Kiss2 genes (Lee et al. 2009b). Eutherian species were thought to possess only the Kiss 1 gene, but a recent study has revealed the presence of a pseudo-Kiss 2 gene, with a highly mutated Kp2(10) sequence (Osugi et al. 2013) in primates, including humans. In sauropsids, various situations have been reported. In squamates, the green anole (Anolis carolinensis) only possesses the Kiss 2 gene, while both the Kiss 1 and Kiss 2 genes have been predicted

Published by Bioscientifica Ltd 
A

\begin{tabular}{|c|c|c|}
\hline Human Kp1 & YNWNSFGLRF & (Lee et al. 1996) \\
\hline Mouse Kp1 & YNWNSFGLRY & (Tomikawa et al. 2012) \\
\hline Opossum Kp1 & YNWNSFGLRY & (Lee et al. 2009b) \\
\hline Platypus Kp1 & YNWNSFGLRY & (Lee et al. 2009b) \\
\hline Crocodile Kp1 & NNSFGLRY & (Pasquier et al. 2014) \\
\hline Chinese turtle Kp1 & NNSFGLRY & (Pasquier et al. 2014) \\
\hline Python Kp1 & LN S F G LRY & (Pasquier et al. 2014) \\
\hline Xenopus Kp1 & WNSFGLRY & (Lee et al. 2009b) \\
\hline Coelacanth Kp1 & NTFGLRY & (Pasquier et al. 2012a) \\
\hline Sea bass $\mathrm{Kp} 1$ & JSFGLRY & (Felip et al. 2009) \\
\hline Zebrafish Kp1 & JNS F GLRY & (van Aerle 2008) \\
\hline European eel Kp1 & NNSFGLRY & (Pasquier et al. 2012a) \\
\hline Spotted gar Kp1 & NNSFGLRY & (Pasquier et al. 2012a) \\
\hline Elephant shark Kp1 & NSFGLRY & (Lee et al. 2009b) \\
\hline Little skate Kp1 & NNSFGLR & (Pasquier et al. 2014) \\
\hline Platypus Kp2 & PFGLR & (Lee et al. 2009b) \\
\hline Mallard duck Kp2-like & FGI & (Pasquier et al. 2014) \\
\hline Crocodile Kp2-like & $F R F$ & (Osugi et al. 2013) \\
\hline Chinese turtle Kp2 & PFGLRF & (Osugi et al. 2013, Pasquier et al. 2014) \\
\hline Python Kp2 & JSFGLR. & (Pasquier et al. 2014) \\
\hline Green anole Kp2 & NPFGLF & (Pasquier et al. 2012a) \\
\hline Xenopus Kp2 & FGL & (Lee et al. 2009b) \\
\hline Coelacanth Kp2 & PFGLR & (Pasquier et al. 2012a) \\
\hline Tetraodon Kp2 & PFGLR & (Pasquier et al. 2012a) \\
\hline Stickleback Kp2 & PFGLI & (Lee et al. 2009b) \\
\hline Sea bass Kp2 & NPFGL & (Felip et al. 2009) \\
\hline Zebrafish Kp2 & YNPFGLF & (Biran et al. 2008) \\
\hline European eel Kp2 & NPFGLF & (Pasquier et al. 2012a) \\
\hline Spotted gar Kp2 & NPFGLF & (Pasquier et al. 2012a) \\
\hline Elephant shark Kp2 & FNPFGLF & (Lee et al. 2009) \\
\hline Little skate Kp2 & NFNPFGLI & (Pasquier et al. 2014) \\
\hline Xenopus Kp3 & NVNSFGL & (Lee et al. 2009b) \\
\hline Coelacanth Kp3-like & NWNSFGLI & (Pasquier et al. 2012a) \\
\hline Elephant shark Kp3-like & NLNSFGLK & (Pasquier et al. 2012a) \\
\hline Sea lamprey Kp-a & YNWNS F G LRF & (Lee et al. 2009b) \\
\hline Sea lamprey Kp-b & FNYNPFGLRF & (Lee et al. 2009b) \\
\hline
\end{tabular}

B

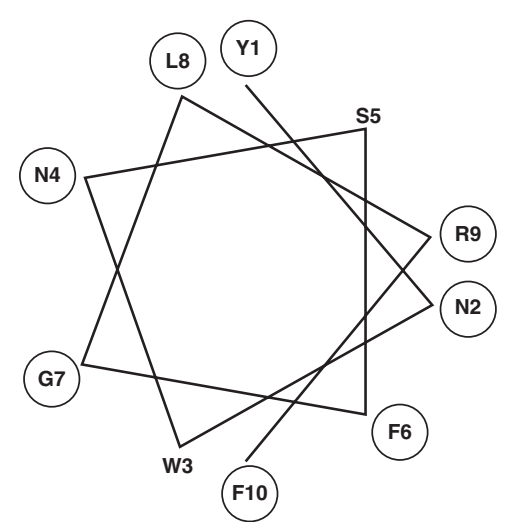

Figure 2

(A) Amino acid sequences of various vertebrate kisspeptin-10 (Kp10). Amino acids are colored according to their physicochemical properties. (B) Schematic helical top view of the human biological active kisspeptin $\mathrm{Kp} 1(10)$. Conserved residues in $\mathrm{Kp}(10)$ vertebrate species are circled. Diagram reworked from http://bioweb2.pasteur.fr/docs/EMBOSS/ pepwheel.html.

in the Indian python genome (Pasquier et al. 2014). Chelonians also possess the Kiss 1 and Kiss 2 genes, as both genes have been detected in multiple turtle genomes (Osugi et al. 2013, Pasquier et al. 2014). In crocodilians, only the Kiss1 gene has been predicted to be potentially functional (Pasquier et al. 2014), while the Kiss2 gene would represent a pseudogene with a highly mutated
Kp2(10) (Osugi et al. 2013; Fig. 2A). Until recently, the Kiss genes were considered to be absent from the genomes of birds. However, our recent phylogenomic investigations revealed the existence of a Kiss 2 pseudogene in the genomes of three bird species, i.e., the mallard duck, the zebra finch, and the rock pigeon (Pasquier et al. 2014). The bird lineage represents, so far, the only example of the absence of functional Kiss genes among vertebrates. In amphibians, Xenopus tropicalis possesses three Kiss genes (Kiss1, Kiss2, and Kiss3) (Lee et al. 2009b). Only Kiss 1 and Kiss 2 transcripts have been described in Xenopus laevis and only Kiss2 in the bullfrog (Rana catesbeiana) (Lee et al. 2009b). Concerning the early sarcopterygians, the Kiss1, Kiss2, and Kiss3 genes have been predicted from the coelacanth (Latimeria chalumnae) genome (Pasquier et al. $2012 b$ ). However, considering the short open reading frame (ORF), Kiss3 should be considered to be a pseudoKiss 3 gene in the absence of further functional evidence (Pasquier et al. 2012b).

In extant actinopterygians, a maximum of two kiss genes (Kiss1 and Kiss2) have been identified. In a holostean species, the spotted gar (Lepisosteus oculatus), Kiss1 and Kiss 2 have been predicted from the genomic data (Pasquier et al. 2012b). To date, in teleosts, two situations have been reported. Only the Kiss 2 gene is present in some species such as fugu (Takifugu niphobles), tetraodon (Tetraodon nigroviridis), and stickleback (Gasterosteus aculeatus) (Pasquier et al. 2012b). In contrast, the Kiss1 and Kiss2 genes have been characterized in some other species including zebrafish (Danio rerio) (Biran et al. 2008), goldfish (Carassius auratus) (Li et al. 2009), medaka (Oryzias latipes) (Lee et al. 2009b), chub mackerel (Scomber japonicus) (Selvaraj et al. 2010), striped bass (Morone saxatilis) (Zmora et al. 2012), and European eel (Pasquier et al. 2012b).

In chondrichthyes, only fragmental genomic databases are currently available. However, the occurrence of the Kiss1, Kiss2, and Kiss3 genes could be predicted from the elephant shark genome (Lee et al. 2009b, Pasquier et al. $2012 b$ ) and the Kiss 1 and Kiss 2 genes from the little skate genome (Leucoraja erinacea) (Pasquier et al. 2014). In cyclostomes, two kiss genes have been predicted from sea lamprey genomic data (Lee et al. 2009b).

\section{Evolutionary history of the Kiss family}

Syntenic analysis allowed us to investigate the origin of the Kiss gene diversity during vertebrate evolution. We found that the three conserved genomic regions containing Kiss genes comprise paralogs from at least eleven gene families (Pasquier et al. 2012b). The members of these families are

Published by Bioscientifica Ltd 


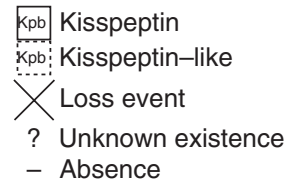

\section{Figure 3}

Current status and proposed evolutionary history of Kiss genes among deuterostomes. The common names of representative species of each lineage are given at the extremity of the final branches, together with the symbols for the Kiss genes they possess. These hypotheses assume the

present among the three Kiss syntenic regions and they also delineate a fourth conserved region, which does not show any Kiss gene in the representative osteichthyan species investigated so far (Pasquier et al. 2012b). These gene families delineate a tetra-paralogon (Fig. 4). On the basis of these observations and in agreement with the vertebrate evolutionary model proposed by Nakatani et al. (2007) (model N), we hypothesize that this tetra-paralogon resulted from the duplications of one single genomic region localized on the proto-chromosome-D of the vertebrate ancestor. Therefore, we inferred that the current three Kiss genes may derive from a single ancestral gene duplicated through the two successive whole-genome duplications ( $1 \mathrm{R}$ and $2 \mathrm{R}$ ) that occurred in the early stages of vertebrate evolution (Figs 3 and 4). After the 1R and 2R events, the history of the Kiss family was driven, all along vertebrate evolution, by multiple and independent pseudogenization processes and gene loss events, leading to the current diversity of Kiss described in the section Diversity of Kiss genes in vertebrates. and illustrated in Figs 3 and 4. The loss of the putative Kiss 4 gene would have occurred early in the history of vertebrates, as it is absent in extant presence of a single Kiss gene ancestor in early chordates leading to four Kiss paralogous genes after the $1 R$ and $2 R$ in early vertebrates. Multiple pseudogenization processes and gene loss events shaped the current vertebrate Kiss gene diversity.

species, as indicated by syntenic analysis. The Kiss 3 gene would have been lost independently in early actinopterygians and early amniotes (Fig. 3). The Kiss1 and Kiss2 genes are the most represented Kiss genes in extant vertebrates. Kiss 1 would have been lost independently in some teleosts and sauropsids, while Kiss 2 would have been lost in some sauropsids and mammals (Fig. 3). Notably, due to massive gene losses, no effect of the teleost-specific third round of whole-genome duplication (3R) can be recorded on the current number of Kiss genes in teleosts (Pasquier et al. 2012a,b; Figs 3 and 4).

Although the current hypothesis on the origin of Kiss diversity assumes the existence of an ancestral Kiss gene in early chordates, no Kiss genes have been identified yet in the genomes of representative species of cephalochordates, hemichordates, or echinoderms (Fig. 3).

\section{Molecular diversity and phylogenetic evolution of KissRs in vertebrates}

KissRs are GPCRs belonging to the rhodopsin gamma family (Mirabeau \& Joly 2013). In vertebrates, their closest

Published by Bioscientifica Ltd 


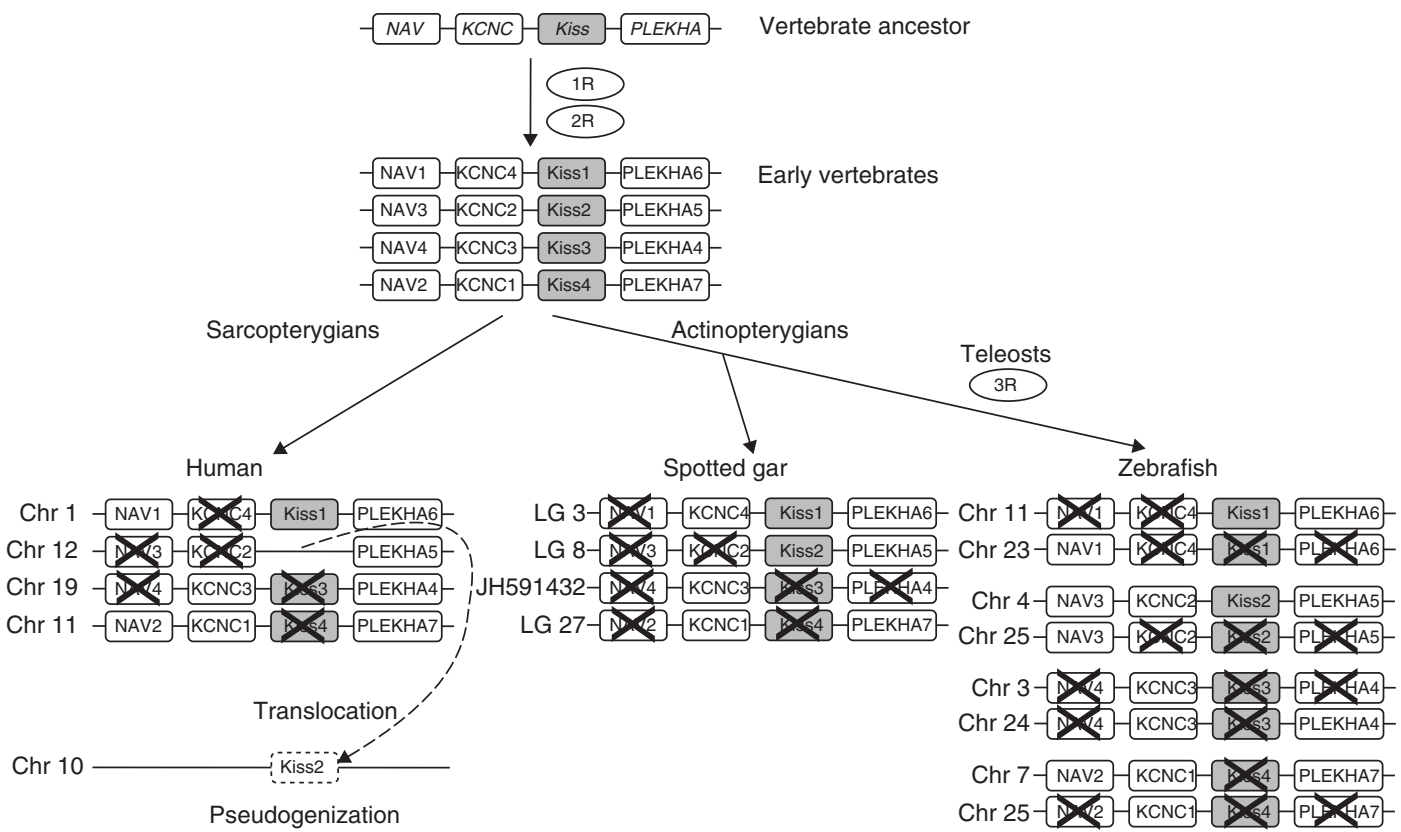

\section{Figure 4}

Proposed origin and evolution of vertebrate Kiss tetra-paralogons. The paralogous genes of several identified families, illustrated here by NAV, $K C N C$, and PLEKHA, delineate a tetra-paralogon in vertebrate (such as spotted gar and human) genomes that originated from $1 R$ and $2 R$. In humans, a pseudo-Kiss 2 gene has been predicted on chromosome 10

relatives are the galanin receptors (Lee et al. 1999, Mirabeau \& Joly 2013). Following the characterization of the single KissR1 gene in eutherian mammals, investigations in various vertebrates revealed the existence of up to four paralogous KissR genes (KissR1, KissR2, KissR3, and KissR4) (Pasquier et al. 2012a,b).

\section{KissR gene structure}

The mammalian KissR1 gene encompasses five exons and four introns, and its structure is well conserved among vertebrates (for review see Tena-Sempere et al. (2012)). However, it has been reported that the medaka Kissr3 gene is made of six exons and five introns (Tena-Sempere et al. 2012).

The existence of kissr mRNA splicing isoforms has been reported in several teleost species including the senegalese sole (two KissR2 isoforms) (Mechaly et al. 2009), the yellowtail kingfish (five KissR2 isoforms) and Southern bluefin tuna (two kissr2 isoforms) (Nocillado et al. 2012), the zebrafish (five kissr3 isoforms) (Onuma \& Duan 2012), and the European eel (three kissr3 isoforms) (Pasquier et al. $2012 a$ ). The splicing variants can result from the retention of an intron as in the senegalese sole (Mechaly et al. 2009),
(Osugi et al. 2013), indicating a translocation and pseudogenization. A duplicated tetra-paralogon is present in teleost (such as zebrafish) genomes, as a result of the 3R. Due to multiple Kiss gene loss, there is no effect of the $3 R$ on the number of Kiss genes in the extant teleost species.

yellowtail kingfish and bluefin tuna (Nocillado et al. 2012), or they can result from the deletion of exonic sequence as in the zebrafish (Onuma \& Duan 2012), yellowtail kingfish (Nocillado et al. 2012), and European eel (Pasquier et al. $2012 a$ ). So far, these splicing variants are considered to give rise to non-functional proteins except for one of the zebrafish truncated isoforms (KRBDP3), which has been located in the nucleus and could exert a transactivation effect upon kisspeptin binding (Onuma \& Duan 2012). The existence of these splicing isoforms for KissR2 and KissR3 in several teleost species indicates the existence of an ancestral post-transcriptional regulatory process for KissR.

\section{Diversity of Kissr genes in vertebrates}

Since the discovery of the first Kiss $R$ in rat, described at that time as a galanin-like receptor and named Gpr54 (Lee et al. 1999), this gene has been identified in most of vertebrate lineages including cyclostomes, teleosts, amphibians, and sauropsids (Lee et al. 2009b, Pasquier et al. 2012b, Tena-Sempere et al. 2012). Phylogenetic and syntenic analyses (Lee et al. 2009b, Kim et al. 2012, Pasquier et al. 2012a,b) revealed that vertebrate species possess up to four paralogous KissR, i.e., KissR1, KissR2,

Published by Bioscientifica Ltd 
KissR3, and KissR4 genes according to the recent classification (Pasquier et al. 2012a).

Among vertebrates, various situations have been observed concerning the number of paralogous KissR genes. The maximal number of KissR has been recently detected in representative species of early sarcopterygians (coelacanth) and actinopterygians (spotted gar), which both possess the four KissR (Pasquier et al. 2012a,b).

In mammals, eutherians possess only the KissR1 gene, while prototherians, such as platypus, have both the KissR1 and KissR4 genes (Fig. 5). In sauropsids, various situations have been reported (Pasquier et al. 2014). In squamates, the green anole (A. carolinensis) only possesses the KissR4 gene, while both the KissR1 and KissR4 genes are predicted in the Indian python genome (Pasquier et al. 2014). Chelonians also possess the KissR1 and KissR4 genes, as both genes are predicted in the soft-shell Chinese turtle and the painted turtle genomes (Pasquier et al. 2014). In crocodilians, only the KissR1 gene has been predicted in the salt-water crocodile, the American alligator, and the Indian gharial (Pasquier et al. 2014). Phylogenetic and syntenic analyses support the absence of
KissR1, KissR2, and KissR3 genes in birds; however, the possible existence of Kissr4 in birds cannot be ruled out due to the incomplete sequencing of bird genomes in the putative region of KissR4 (Pasquier et al. 2014). Among tetrapods, amphibians present the largest number of KissR, with three KissR in X. tropicalis (KissR1, KissR2, and KissR3) (Lee et al. 2009b), while only the KissR2 transcript has been identified in the bullfrog (Moon et al. 2009) and the edible frog (Chianese et al. 2013).

In teleosts, different situations have been observed. All teleost species investigated so far express the KissR2 gene (Tena-Sempere et al. 2012). However, some species also possess the KissR3 gene, including zebrafish (D. rerio) (Biran et al. 2008), goldfish (C. auratus) (Li et al. 2009), medaka (O. latipes) (Lee et al. 2009b), striped bass (M. saxatilis) (Zmora et al. 2012), chub mackerel (S. japonicus) (Ohga et al. 2013), and European eel (Anguilla anguilla) (Pasquier et al. 2012a). In addition, the eel presents the peculiarity of being the only teleost species possessing a kissR1 gene orthologous to the mammalian KissR1. With three different kissr, the eel is also the teleost species possessing the largest diversity of kissr genes.

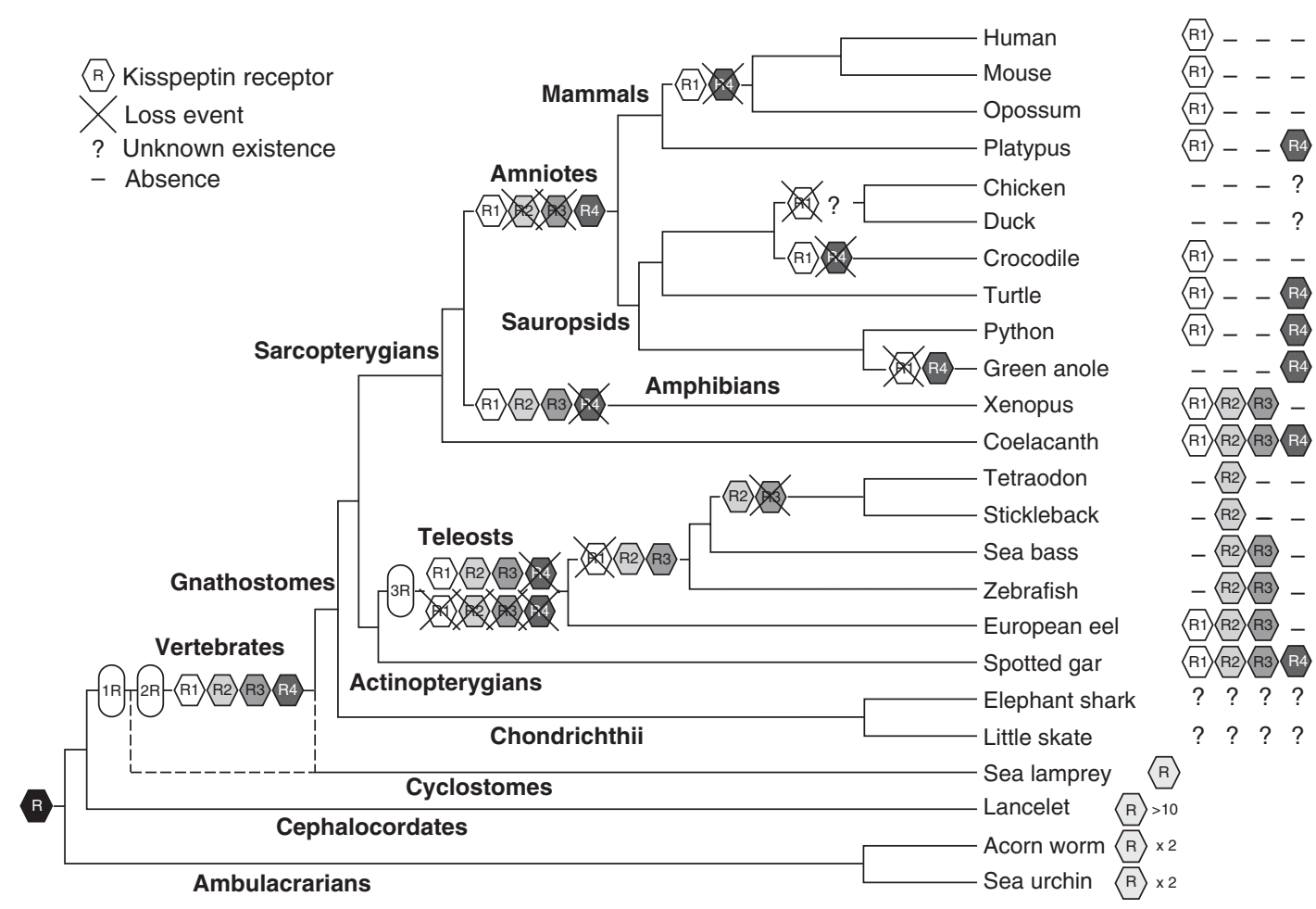

Figure 5

Current status and proposed evolutionary history of Kisspeptin receptor (KissR) genes among deuterostomes. The common names of representative species of each lineage are given at the extremity of the final branches, together with the symbols for the KissR genes they possess. (c) 2014 Society for Endocrinology Printed in Great Britain
These hypotheses assume the presence of a single Kiss $R$ gene ancestor in early chordates leading to four Kiss $R$ paralogous genes after the $1 R$ and $2 R$ in early vertebrates. Multiple pseudogenization processes and gene loss events shaped the current vertebrate KissR gene diversity.

Published by Bioscientifica Ltd 
To date, no KissR gene has been identified in cartilaginous fish. In cyclostomes, one KissR gene has been predicted from the sea lamprey genome (Pasquier et al. 2012a). KissR homologous genes have been found in the genomes of representative species of non-vertebrate deuterostomes, such as cephalochordates (lancelet) (Holland et al. 2008), hemichordates (acorn worm), and echinoderms (sea urchin) (Pasquier et al. 2012a) (Fig. 5).

\section{Evolutionary history of KissR family}

Syntenic analysis has revealed that the four genomic regions neighboring KissR genes are highly conserved, each presenting paralogs from at least eight gene families (Pasquier et al. 2012a). On the basis of these observations and in agreement with the chordate evolutionary models proposed by Putnam et al. (2008) (model P) and by Nakatani et al. (2007) (model N), we hypothesize that this tetra-paralogon originates from the duplications of one single genomic region localized on the chordate proto-chromosome-1 (according to model $\mathrm{P}$ ) and the vertebrate proto-chromosome-A (according to model $\mathrm{N}$ ). Therefore, we propose that the current four KissR genes may have resulted from a single ancestral gene duplicated through the whole-genome duplication events, $1 \mathrm{R}$ and $2 \mathrm{R}$, that occurred in early steps of vertebrate evolution (Figs 5 and 6). Actually, four paralogous KissR genes are still present in some extant vertebrate species, including the coelacanth and the spotted gar (Figs 5 and 6). The hypothesis of the KissR tetra-paralogon suggests that a $K i s s R$ ancestral gene was present before the emergence of vertebrates (Figs 5 and 6). In agreement with this hypothesis, KissR homologous genes have been identified in non-vertebrate deuterostomes (Fig. 5).

To date, phylogenetic analyses of the KissR family do not allow the homology relationships between the four KissR resulting from the 2R (Pasquier et al. 2012a,b) to be fully solved. However, one of the most recent phylogenetic reconstructions has indicated that KissR1 and KissR3 could be sister groups after the 2R (Pasquier et al. 2014). In addition, a recent study has proposed the phylogenetic reconstruction of a gene family associated with the KissR paralogon, the PALM family (Hultqvist et al. 2012). This study, which provides indirect insights into the relationships between the four $K i s s R$, strengthens the hypothesis of sister KissR1 and KissR3, on the one hand, and sister KissR2 and KissR4, on the other hand, resulting from the $2 \mathrm{R}$.

After the $1 \mathrm{R}$ and $2 \mathrm{R}$ events, the history of the KissR family was driven, throughout vertebrate evolution, by

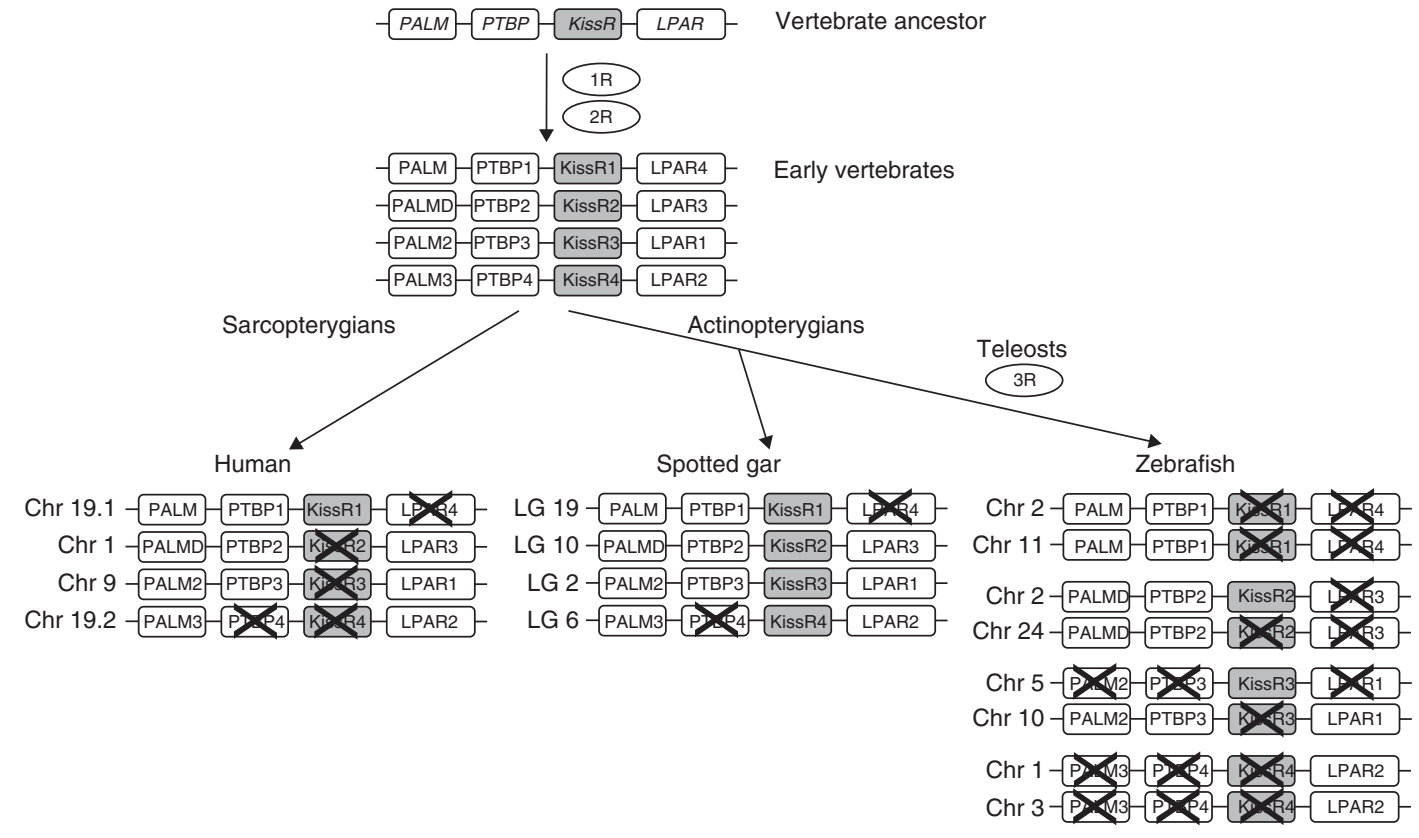

\section{Figure 6}

Proposed origin and evolution of vertebrate KissR tetra-paralogons. The paralogous genes of several identified families, illustrated here by $P A L M, P T B P$, and $\angle P A R$, delineate a tetra-paralogon in vertebrate (such as spotted gar and human) genomes that originated from $1 R$ and $2 R$.
A duplicated tetra-paralogon is present in teleost (such as zebrafish) genomes, as a result of the $3 R$. Due to multiple $K i s s R$ gene loss, there is no effect of the $3 R$ on the number of kissr genes in the extant teleost species. http://jme.endocrinology-journals.org DOI: 10.1530/JME-13-0224
() 2014 Society for Endocrinology Printed in Great Britain
Published by Bioscientifica Ltd 
multiple gene loss events leading to the current diversity of KissR described in the section Diversity of KissR genes in vertebrates and illustrated in Figs 5 and 6 . KissR4 would have been lost independently in the actinopterygian and sarcopterygian lineages. Among actinopterygians, this event would have occurred after the emergence of holosteans (such as the spotted gar) in a teleost ancestor. Among sarcopterygians, KissR4 would have been lost independently in the amphibians, eutherian mammals, and some sauropsids. KissR3 would have been lost independently in some teleosts and in early amniotes. KissR2 would have been lost only in the amniote lineage. As mentioned for Kiss genes (see section Evolutionary history of the Kiss family), due to massive gene losses, no effect of the teleost-specific third round of wholegenome duplication (3R) can be recorded on the current number of KissR in teleosts (Pasquier et al. 2012a,b; Figs 5 and 6).

\section{Evolution of kisspeptin and KissR pairs}

As a consequence of the independent losses of Kiss genes as well as of KissR genes, the extant vertebrate species present various combinations of putative Kiss and KissR couples. For example, the same Kiss genes, Kiss 1 and Kiss2, are present in various species from two distant lineages, amniotes and teleosts, while these species possess different KissR genes. In amniotes, only Kissr1 and/or Kissr4 are conserved. In contrast, in teleosts, all species kept KissR2, a few species also kept KissR3, and only the eel conserved the KissR1 ortholog. This situation, which results from multiple independent loss events, challenges the former hypothesis of a conservation of Kiss/KissR pairs across vertebrate evolution. Another example of nonconservation of specific Kiss/KissR pairs is provided by some vertebrate species, such as the spotted gar, the European eel, and the coelacanth, presenting a larger number of KissR than Kiss genes.

The strong conservation of the biologically active $\mathrm{Kp}(10)$ sequences among Kiss types and vertebrate species (see section Molecular diversity and phylogenetic evolution of kisspeptins in vertebrates and Fig. 2A) may have favored the lack of conservation of specific Kiss/KissR pairs across vertebrate evolution. As a matter of fact, in vitro studies have shown that the different KissR can be independently activated by any kisspeptin (Lee et al. 2009b, Li et al. 2009, Onuma \& Duan 2012).

Other evolutionary factors than co-evolution between specific Kiss and KissR may have therefore driven the conservation of multiple Kiss and KissR in various vertebrate species. They may concern differential properties and physiological roles, such as differential tissue expression, differential regulation, and mechanisms of action.

\section{Structure-activity relationships and evolution of kisspeptins}

Human kisspeptin-10 (hKp1(10)) (YNWNSFGLRF-NH2) corresponds to the carboxy-terminal decapeptide sequence of kisspeptin1-54, (hKp1(54)), kisspeptin1-14 (hKp1(14)), and kisspeptin1-13 (hKp1(13)), three molecular forms purified from human placenta (Kotani et al. 2001). Synthetic hKp1(10) binds to KissR1, acts on intracellular messengers, and inhibits cell culture proliferation with the same efficacy as the longer kisspeptins (Kotani et al. 2001, Ohtaki et al. 2001). This decapeptide thus bears the biological activity of kisspeptins.

Many studies have been conducted to identify the amino acids involved in kisspeptin activity. Design and synthesis of downsized hKp1(54) analogs have demonstrated that the five hKp1(10) C-terminal residues play a significant role in receptor binding and activation (Niida et al. 2006). On rat Kp1(10) (that differs from human Kp1(10) by a C-terminal amidated tyrosine instead of an amidated phenylalanine), substituted analogs in which each residue was systematically replaced by alanine (Ala-scan) confirmed the importance of the aromatic residues Phe6 and Tyr10 in agonistic activity (Gutiérrez-Pascual et al. 2009).

NMR studies of hKp1(13) in a solution of SDS micelles showed that the peptide is structured in a helix on its C-terminal half with Phe9, $\operatorname{Arg} 12$, and Phe13 residues (respectively 6, 9 and 10 in hKp1(10) numbering) positioned on the same face of the helix (Orsini et al. 2007). In a schematic top view representation of the helix (Fig. 2B), the Asn2 residue appears to be also positioned on the same side, between Phe6 and Arg9. Ala-scan experiments on human Kp1(10) indeed demonstrated that this Asn2 residue is essential for receptor binding (Curtis et al. 2010). It should be noticed that the conformation of hKp1(10) depends on the membrane mimetic environment in which it is located. In dodecylphosphocholine (DPC) micelles, NMR analysis showed that the region encompassing the residues Trp3 to Phe10 contained several tight turns, but no helical conformation, with Leu8 in the same hydrophobic cluster as Phe6 and Phe10 (Lee et al. 2009a). Rat Kp1(10) mainly adopts an helical conformation in diphenylcarbodiimide (DPCD) micelles, from Asn 4 to Tyr10, with a combination of $\alpha$ and 3(10) helix, and a disordered N-terminal region (Gutiérrez-Pascual et al. 2009).

Published by Bioscientifica Ltd 
Residues that play a crucial role in kisspeptin activity, namely Asn2, Phe6, Arg9 and the C-terminal aromatic residue Phe10 or Tyr10, are conserved in all vertebrate species from coelacanth to human (Fig. 2A and B). The presence of Asn 4 in the helix is also fundamental and this residue is strictly conserved in all species (Fig. 2A and B). Consistent with this notion, a Kiss1 variant has been recently described in a patient with idiopathic $\mathrm{HH}$, where the substitution of Asn 115 (position 4 in hKp1(10)) with a lysine altered the peptide activity, possibly by modifying its 3D structure (Topaloglu et al. 2012).

The chirality and the aromatic properties of the two C-terminal residues (Arg and Phe or Tyr) are also essential to $\mathrm{hKp1(10)}$ activity. Replacement of these residues by their D-enantiomers (Niida et al. 2006) or substitution by saturated-side-chain amino acids (Orsini et al. 2007) suppresses their biological activity. In contrast, substitution of some amino acids of the N-terminal end with their D-enantiomers can improve the peptide activity and/or its resistance to proteases. For instance, replacement of Trp3 by D-Trp yields to a compound with high metabolic stability in serum and good agonistic activity (Asami et al. 2012). Similarly, substitution of Tyr1 by D-Tyr increases the biological activity of the peptide in vivo (Curtis et al. 2010). A LC-MS/MS assay has been recently developed to quantify $\mathrm{Kp}(10)$ levels in rat plasma. Using this method, stability studies demonstrated that the peptide is rapidly degraded with a half-life of $1.7 \mathrm{~min}$ at $37^{\circ} \mathrm{C}$, the main degradation product being the $\mathrm{N}$-terminal tyrosine-deleted peptide (Liu et al. 2013). It is also worth noting that Arg9 methylation confers greater resistance of the peptide to trypsin while improving its agonistic potency (Asami et al. 2012).

Several natural variants of the Kiss 1 gene in $\mathrm{HH}$ patients have now been reported (Semple et al. 2005), but only one occurred on the C-terminal end of the molecule at Asn115 (Asn4 in hKp1(10)), as described above (Topaloglu et al. 2012). In contrast, residues at positions 3 and 5 (Trp3 and Ser5 in hKp1(10)), that are the most variable in vertebrates (Fig. 2A and B), are relatively tolerant of Ala substitution (Gutiérrez-Pascual et al. 2009, Curtis et al. 2010).

\section{Structure-activity relationships and evolution of KissRs}

Human KissR1 (Q969F8 UniProtKB), a 398-amino acid protein, belongs to the superfamily of class A rhodopsinlike GPCRs. It comprises an extracellular N-terminal domain of $\sim 50$ residues, followed by seven transmembrane helices (TM1 to TM7) and ends with a C-terminal cytoplasmic domain of about 70 residues (Supplementary Figures 1 and 2, see section on supplementary data given at the end of this article). The seven helices are connected by three intracellular loops, i1, i2, and i3, and three extracellular loops, e2, e3, and e4 (Supplementary Figure 1; Baldwin 1993, Bockaert \& Pin 1999). Human KissR1 has three $\mathrm{N}$-glycosylated asparagine residues (N10, N18 and N28) located in the N-terminal domain (Clements et al. 2001) and a disulfide bridge involving cysteines 115 and 191, joining e2 and e3 (Supplementary Figure 1). These latter cysteines are conserved in vertebrate KissR sequences, as exemplified by the multiple KissR of an early teleost, the eel, and an early sarcopterygian, the coelacanth (Supplementary Figure 1). Globally, strong identity is observed in TM1 to TM4 and TM7 regions, whereas great variability occurs in the $\mathrm{N}$ - and C-terminal domains (Supplementary Figure 1). The threedimensional conformations of eel and coelacanth Kiss receptors show the same typical overall structure of GPCRs as human KissR1, but with some variations at the $\mathrm{N}$ and $\mathrm{C}$ ends (Supplementary Figure 2).

Site-directed mutagenesis and molecular simulation showed the importance of Asp139 and Arg140 in TM3 for mediating receptor activation (Scheer et al. 1996), and these residues are conserved in other vertebrates, including eel and coelacanth KissR (Supplementary Figure 1). An increasing number of mutations involved in $\mathrm{HH}$ in humans and mice have been described in all regions of the KissR molecule (Wahab et al. 2011, Dungan Lemko \& Elias 2012), for instance the substitution of Leu148 by serine in i2 (Seminara et al. 2003). Biochemical and pharmacological analyses have demonstrated that this Leu residue, which is highly conserved in class A GPCRs, is implicated in receptor coupling through hydrophobic interactions with the $\mathrm{G} \alpha$ subunit (Wacker et al. 2008; Supplementary Figure 1).

The cytoplasmic C-terminal domain of the human receptor contains a proline $(\mathrm{P})$ and arginine $(\mathrm{R})$-rich region, including three PRR repeats, that may be organized spatially in overlapping segments and constitute a binding domain for Src homology 3 (SH3) proteins (Saksela \& Permi 2012). SH3 domains, which are directly involved in protein-protein associations, are found, for example, within proteins implicated in signal transduction, such as tyrosine kinases. This C-terminal intracytoplasmic region directly binds to the catalytic and regulatory subunits of phosphatase $2 \mathrm{~A}$ and can form complexes with protein partners involved in receptor signaling (Evans et al. 2008). We also know that arginine-prolinerich motifs are implicated in folding and transport of

Published by Bioscientifica Ltd 
multimeric membrane proteins (Michelsen et al. 2005). A human KissR1 mutation in this region has been recently reported (Chevrier et al. 2013). It consists of the heterozygous insertion of an additional PRR motif in frame with the three PRR repeats, resulting in the synthesis of a receptor with four PRR motifs. This insertion has a dominant negative effect on the WT receptor and causes isolated $\mathrm{HH}$. Molecular dynamics analysis showed that the addition of this PRR stiffened the C-terminal end giving it a polyproline type II helix (PPII), whereas in the WT KissR1 this region had a very flexible conformation. The altered flexibility of the C-terminal tail modifies its interaction with partner proteins (Chevrier et al. 2013). In this regard, it is interesting to note that, in a case of precocious puberty, an Arg386Pro mutation located in the C-terminal region induces a sustained response to Kiss activation (Teles et al. 2008, Bianco et al. 2011). This PRR repeat pattern is not found in non-mammalian vertebrate KissR proteins (Supplementary Figure 1), which indicates an evolutionary variability in signal transduction and/or intracellular trafficking mechanisms.

Molecular modeling of the human KissR1 3D structure by the on-line platform I-Tasser (Roy et al. 2010; Supplementary Figure 2) predicted that the ligandbinding sites were in a cavity formed by residues of TM3 (Gln122, Gln123, Val126, Gln127), e3 (Tyr190, Cys191, Glu193), TM5 (Asn208, Tyr213), TM6 (Leu271, Trp276, Ile279, Gln280), and TM7 (His309, Tyr313). Remarkably, almost all these residues are conserved in vertebrates, as shown in Supplementary Figure 1 for the eel and coelacanth KissR, indicating that their putative function in ligand binding has been conserved through evolution.

\section{Interaction and evolution of Kiss/KissR pairs}

The key C-terminal residues of Kp1(10), namely Phe6, Arg9, and Phe10 and to a lesser extent Leu8, are thought to play a major role in the access to a hydrophobic pocket of the receptor (Orsini et al. 2007). The nature and orientation of the C-terminal side chain residues of Kp1(10) are important for binding and receptor activation (Niida et al. 2006, Tomita et al. 2006), while the C-terminal aromatic residue (Tyr or Phe) is essential for binding (Gutiérrez-Pascual et al. 2009). Amidation of the peptide is also crucial, since Kp1(10) with a free C-terminal carboxyl group is inactive (Ohtaki et al. 2001). The carboxyamide group may interact with the receptor by hydrogen bonding (Tomita et al. 2006). The observation that human Kp1(13) and rat $\mathrm{Kp} 1(10)$ have a common helical domain in their C-terminal part and that they are both full KissR1 agonists strongly indicates that the helix plays a role in the binding and the activation of the receptor. In support of this notion, substitution of the C-terminal Tyr of rat Kp1(10) by Ala, which disrupts the helical structure over the last two amino acids, suppresses binding of the analog to KissR1 (Orsini et al. 2007, Gutiérrez-Pascual et al. 2009).

To activate KissR, Kp1(10) may first need to be incorporated into the lipid membrane and transported to the receptor (Lee et al. 2009a). Indeed, structural studies based on Kp1(10) analogs in 1-palmitoyl-2-oleoyl-phosphatidylcholine (POPC) micelles indicated that the peptide does not directly interact with KissR1, but has to be inserted in the lipid membrane first before diffusing laterally toward the receptor. NMR studies using DPC micelles have shown that the C-terminal end of Kp1(10) forms a hydrophobic cluster consisting of Phe6 and Phe10 and the aliphatic chain of Leu8, which probably interacts with the carbon chains of the inner membrane phospholipids (Lee et al. 2009a). The N-terminal region may also interact with the receptor as kisspeptin photoaffinity probe experiments with Kp1(54) and Kp1(14) show that the three N-terminal residues (Tyr, Asn, and Trp) can constitute a secondary binding site with KissR1 (Misu et al. 2013).

Thus, it is assumed that Kp1(10) adopts a helical conformation near the cell surface that enables the peptide to insert into the phospholipidic bilayer by hydrophobic and electrostatic interactions. This mechanism of insertion into eukaryotic cells is commonly described for antimicrobial peptides which are about the same size as Kp1(10), are carboxyamidated, adopt a helical conformation, and establish electrostatic and hydrophobic interactions with membrane phospholipids (Li et al. 2012).

Regarding the KissR, we do not know yet how it accommodates the ligand. For rhodopsin, whose 3D structure is known (Unger et al. 1997, Palczewski et al. 2000) and which belongs to the same class A GPCRs, the ligand binds in a pocket formed by TM2 to TM6. In this case, light causes a conformational change of retinal covalently bound in this cavity, leading to receptor activation. This activation is associated with an 'opening' of the receptor due to the rotation of TM6, which results in the uncovering of the G-protein-binding sites. The i2 and i3 intracellular loops are mainly involved in the interaction with the G protein (Farrens et al. 1996, Bourne 1997, Bockaert \& Pin 1999) and are essential for the activation of Gs (Arora et al. 1998).

Finally, binding of Kiss to KissR1 may generate mono-, di- or oligomeric structures, as different quaternary structures are observed for Class A GPCRs, following agonist binding (Gurevich \& Gurevich 2008,

Published by Bioscientifica Ltd 
Pellissier et al. 2011). In the case of non-mammalian vertebrate species, which express several KissR types, formation of heterodimers may be hypothesized to occur as already shown for other GPCRs (Vilardaga et al. 2010).

\section{Signaling pathways activated by Kiss/KissR pairs}

\section{Signaling pathways in mammals}

The three initial studies reporting the characterization of KissR1 (GPR54, AXOR12, or hOT7T175) as the receptor for kisspeptins also investigated the intracellular signaling pathways activated by this receptor (Fig. 7; Kotani et al. 2001, Muir et al. 2001, Ohtaki et al. 2001, Asami et al. 2012). These studies, which used heterologous cell models, transfected with the rat or human KissR1 (CHO-K1 (Kotani et al. 2001), HEK293 (Muir et al. 2001), and B16-BL6 (Ohtaki et al. 2001)), showed that in mammals, the phospholipase C (PLC)/protein kinase C (PKC)/MAPK pathway was activated (for reviews Castaño et al. (2009) and Pinilla et al. (2012)). Using transient transfections of HEK293 (Muir et al. 2001) and CHO-K1 (Kotani et al. 2001) cell lines, the authors reported that calcium mobilization was observed after the activation of KissR and not altered by treatment with pertussis toxin. These results indicated that KissR was coupled to $G$ proteins of the Gq/11 subfamily. This hypothesis was further strengthened by the fact that

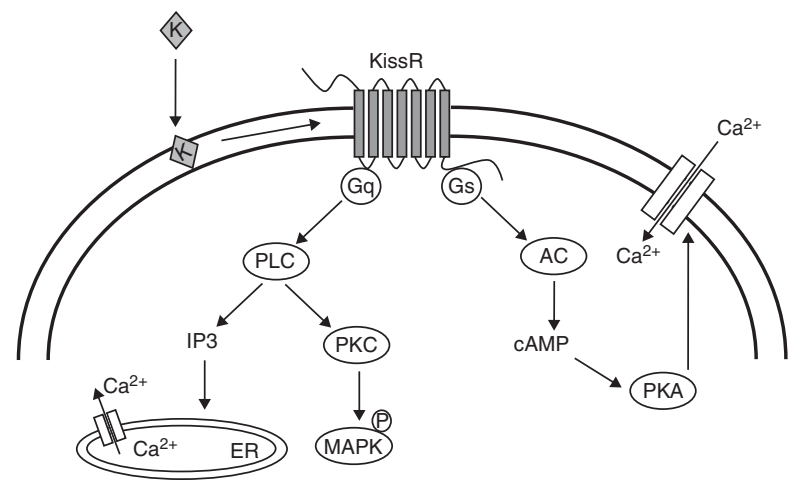

\section{Figure 7}

Schematic representation of the Kiss/KissR signaling pathways. Kisspeptin $(K)$ is translocated along the phospholipid bilayer toward its receptor (KissR), a seven-transmembrane-domain G-protein-coupled receptor. The main signaling pathway involves $\mathrm{Gq}$ protein and activation of phospholipase C (PLC). PLC is a crossroads of two activation pathways: one leading to MAP kinase phosphorylation (MAPKP) via protein kinase C (PKC) and the other leading to endoplasmic reticulum (ER) calcium mobilization via phosphatidylinositol-3-kinase (IP3) activation. In teleosts, which possess more than one KissR, the adenylate cylcase (AC)/ protein kinase A (PKA) signaling pathway can also be activated, leading to a rise in extracellular $\mathrm{Ca}^{2+}$ influx. kisspeptin did not modify basal or forskolin-induced cAMP levels, showing that KissR does not couple strongly to Gs and/or Gi/o subfamilies. Kotani et al. (2001) demonstrated that kisspeptins stimulated arachidonic acid release and phosphorylation of MAP kinases (extracellular signalregulated kinases, ERK1 and ERK2). They also reported a weak stimulation of p38 MAP kinase phosphorylation but not of stress-activated protein kinase/c-Jun NH2-terminal kinase (SAPK/JNK). Activation of the MAP kinase-related pathways by kisspeptins was also reported using B16-BL6 mouse melanoma cells stably expressing KissR1 (Ohtaki et al. 2001). In COS-7 cells transiently transfected with cDNAencoding mouse KissR1, kisspeptin increases intracellular IP3 production (Stafford et al. 2002).

Linked to the description of kisspeptin (metastin) as an inhibitor of metastasis, some in vitro studies have been carried out on cancer cell lines. In anaplastic thyroid cancer cells (ARO) expressing endogenous KissR1, Ringel et al. (2002) showed that treatment with kisspeptin (metastin) causes activation (phosphorylation) of ERK, but neither Akt nor p38. Three years later, Stathatos et al. (2005) created a stable KissR1 overexpression model using KissR1-null papillary thyroid cancer cells (NPA cell line), instead of using ARO cells which express endogenous KissR1. Similarly to ARO cells but in contrast to previous results (Ringel et al. 2002), exposure of transfected NPA cells to kisspeptin (metastin) provoked phosphorylation of Akt, p42/44 MAPK, and PKC. Specific blockers of phosphatidylinositol-3-kinase and MAPK did not alter kisspeptin (metastin)-mediated metastasis inhibition (Stathatos et al. 2005). Different effects on MAPK activation have also been obtained with pancreatic cancer cell lines expressing endogenous KissR1 (Masui et al. 2004). The authors chose the AsPC-1 cell line for its high KiSS1 and low KissR1 expression level, and the PANC-1 cell line for its low KiSS1 and high KissR1 expression level. Kisspeptin (metastin) was able to inhibit cell migration in PANC-1, but not in AsPC-1. ERK1 phosphorylation was activated in both cell lines by kisspeptin treatment, while an increase in p38 phosphorylation was only observed in PANC-1 cells. Becker et al. (2005) established a recombinant expression system in the human MDA-MB-435S cell line, originating from a metastatic ductal breast carcinoma, in order to investigate the intracellular mechanisms involved in the reduction of their metastatic potential. The transcription of all microarray-identified genes was abolished by the use of inhibitors of PLC, PKC, and p42/44 MAP kinases (Becker et al. 2005).

Some other in vitro studies were then conducted in a physiologically relevant context in terms of control of

Published by Bioscientifica Ltd 
reproductive function, using cultured hypothalamic explants (Castellano et al. 2006), hypothalamic slices (Choe et al. 2013), rat pituitary cells (Gutiérrez-Pascual et al. 2007), baboon pituitary cells (Luque et al. 2011) and the L $\beta$ T2 pituitary gonadotrope cell line (Witham et al. 2013). Castellano et al. (2006) explored the signaling cascades involved in kisspeptin-induced GNRH secretion by means of pharmacological blockade using rat hypothalamic explants. A PLC inhibitor totally suppressed kisspeptin-induced the GNRH secretion, whereas an adenylate cyclase (AC) blocker failed to modify the GNRH response to kisspeptin-10 (Castellano et al. 2006). In addition, the ability of kisspeptin to induce GNRH secretion was abrogated after depletion of intracellular $\mathrm{Ca}^{2+}$ stores by thapsigargin, while blockade of extracellular $\mathrm{Ca}^{2+}$ entry by cadmium did not affect the GNRH secretory response to kisspeptin (Castellano et al. 2006). Treatments with blockers of ERK1/2 and p38 kinases were able to totally prevent kisspeptin-stimulated GNRH secretion, whereas inhibition of Jun N-terminal kinase only partially reduced GNRH responses to kisspeptin. In two GNRH-secreting neuronal cell lines (GT1-7 and GN11), which express KissR, pretreatment with a ERK1/2 MAPK inhibitor and a PI3K inhibitor attenuated the effects of kisspeptin on GNRH mRNA expression (Novaira et al. 2009). Choe et al. (2013) used cultured hypothalamic slices prepared from transgenic mice expressing a GNRH promoter-driven luciferase reporter, and confirmed the involvement of PKC in kisspeptin signaling in GNRH stimulation. Using the L $\beta \mathrm{T} 2$ pituitary gonadotrope cell line transfected with KissR1, Witham et al. (2013) reported that PKC signaling was required for kisspeptin-mediated induction of $L H \beta$ and $F S H \beta$ gene expression, as treatment with a PKC inhibitor significantly decreased the effect of kisspeptin on $L H \beta$ and $F S H \beta$ promoters. Using cultured pituitary cells from peripubertal male and female rats, Gutiérrez-Pascual et al. (2007) showed that kisspeptin acts on a subset of gonadotrophs and somatotrophs by increasing cytosolic $\mathrm{Ca}^{2+}$ levels. By means of a panel of pharmacological intracellular signaling blockers in primary baboon pituitary cell cultures, Luque et al. (2011) demonstrated that $\mathrm{Kp}(10)$ signals through PLC, PKC, MAPK, and intracellular $\mathrm{Ca}^{2+}$ mobilization, but not through AC, protein kinase A (PKA), extracellular $\mathrm{Ca}^{2+}$ influx, nor nitric oxide synthase, to stimulate both LH and GH release.

Following the discovery by De Roux et al. (2003) and Seminara et al. (2003) of a link between mutation of KissR1 and the occurrence of $\mathrm{HH}$ in humans, clinical studies on mutated KissRs also contributed to a better understanding of kisspeptin system signaling pathways. Seminara et al. (2003) determined whether the identified changes in KissR1 affected the function of the receptor by measuring inositol phosphate (IP) production in COS-7 cells transfected with mutant constructs. They found that substitution of Leu148 by Ser (L148S) markedly reduced production as compared with the WT construct. As mentioned earlier (section Structure-activity relationships and evolution of kisspeptin receptors), Leu148 is highly conserved in vertebrates. In 2005, two novel missense mutations in KissR1 were found in a patient with $\mathrm{HH}$, i.e., substitutions of Cys223 by Arg (C223R) and of Arg297 by Leu (R297L) (Semple et al. 2005). Flp-In-293 cells expressing the $C 223 R$ mutation variant were found to exhibit profoundly impaired signaling, with low calcium mobilization, while the other mutation variant (R297L) gave rise to mild reduction in ligand-stimulated activity (Semple et al. 2005). Remarkably, Cys223 is highly conserved among vertebrate KissR, while large amino acid variations are observed for Arg297 (Supplementary Figure 1). This further indicates a strong correlation between evolutionary sequence conservation and key function of KissR amino acids. Tenenbaum-Rakover $\mathrm{et} \mathrm{al}$. (2007) reported a novel mutation in KissR1, a Leu substitution with Pro at residue 102 (L102P), in five patients with $\mathrm{HH}$ belonging to two unrelated families. The mutated receptor expressed in HEK 293 cells showed virtually no IP accumulation after kisspeptin stimulation, compared with the WT receptor (Tenenbaum-Rakover et al. 2007). As mentioned earlier (section Structureactivity relationships and evolution of kisspeptin receptors), Leu102 is highly conserved among vertebrates. In 2008, a KissR1-activating mutation (substitution of Pro386 by Arg) was discovered in a girl with idiopathic central precocious puberty (Teles et al. 2008). The authors found out that this mutation led to prolonged activation of intracellular signaling pathways in response to kisspeptin, i.e. more sustained elevation of IP levels and slower decrease in phosphorylation of ERK levels, as well as prolonged binding at the plasma membranes. As discussed earlier (section Structure-activity relationships and evolution of kisspeptin receptors), this C-terminal intracellular region of KissR shows large sequence variations among vertebrates, indicating possible species-specific mechanisms of intracellular signaling.

\section{Signaling pathways in non-mammalian vertebrates}

Studies on signal transduction pathways of the kisspeptin system in non-mammalian vertebrates are still scarce.

Published by Bioscientifica Ltd 
In 2009, using CRE-luc and SRE-luc reporter systems, which are known to discriminate the AC/PKA and PLC/PKC signaling pathways, respectively, Moon et al. (2009) demonstrated that in CV-1 cells transfected with bullfrog GPR54 (KissR2 in our nomenclature), kisspeptin induced SRE-driven luciferase activity but not CRE-driven luciferase activity. Pretreatment of these cells with a PKC inhibitor (to inhibit Gq-mediating signaling) markedly reduced SRE-luc activity, while pretreatment with a Rho kinase inhibitor (to inhibit $\mathrm{G}_{12 / 13}$-mediating signaling) only slightly reduced SRE-luc activity. Similar to mammalian KissR1, this indicates a preferential coupling of amphibian KissR2 to the Gq protein-PKC pathway rather than to the Gs-mediated signaling pathways (Moon et al. 2009). In $X$. tropicalis, in which a triplicate kisspeptin system has been characterized, Lee et al. $(2009 a, b)$ reported that all three KissR (KissR1, KissR2, and KissR3) were activated by the three kisspeptins as determined from SRE-luc promoter activity. This indicates that all three Xenopus KissR types are signaling through the PKC pathway; however, no such comparative investigation has been reported concerning the PKA pathway.

In teleosts, in the orange-spotted grouper (Shi et al. 2010), which possesses a single Kiss/KissR couple (Kiss2/ KissR2 in our nomenclature), Kp2(10) was able to increase SRE promoter activity, but not the activity of the CRE pathway in COS-7 cells transiently transfected with KissR2. Similarly, Nocillado et al. (2012) showed that Southern bluefin tuna KissR2 and yellowtail kingfish KissR2 preferentially transduced via the PKC than PKA pathways (Nocillado et al. 2012). In zebrafish, which possesses two Kiss (Kiss1 and Kiss2) and two KissR (Kiss1Ra and Kiss $1 \mathrm{Rb}=$ KissR2 and KissR3 in our nomenclature, respectively), differential activation of signaling pathways has been observed using COS cells transfected with zebrafish KissR and SRE-/CRE-reporters (Biran et al. 2008). While Kiss1Ra (KissR2) signaled preferentially via the PKC pathway, Kiss1Rb (KissR3) was able to activate both the PKC and PKA pathways (Biran et al. 2008). Similar results were obtained in another cyprinid, the goldfish (Li et al. 2009). A recent study in a perciform, the chub mackerel, which also possesses two KissR types, has indicated that both receptors activated the PKC pathway, while only one was able to activate PKA (Ohga et al. 2013). Differential signaling pathways (Fig. 7), as shown in those teleost species, may have contributed to the conservation of multiple KissR in vertebrates. Future studies should aim at investigating the signaling pathways in the eel, the only teleost species possessing up to three KissR types (Pasquier et al. 2012a).

\section{Conclusion}

Studies in various vertebrate species have revealed the existence of multiple paralogous genes coding for Kiss and KissR. This diversity was probably generated by the two whole-genome duplication events, $1 \mathrm{R}$ and $2 \mathrm{R}$, that occurred in early vertebrates. Independent gene losses, throughout vertebrate evolution, led to the presence of various numbers and types of Kiss and KissR, in the extant vertebrate species. In particular, there was no conserved combination of a given Kiss type with a KissR type, across vertebrate evolution. The striking conservation of the biologically active ten-amino-acid C-terminal sequence of all vertebrate kisspeptins probably allowed this evolutionary flexibility in the Kiss/KissR pairs. KISSR mutations, responsible for $\mathrm{HH}$ in humans, mostly correspond to highly conserved amino acid positions among vertebrate KissR. This further highlights the key function of these amino acids. Cross talk between evolutionary and biomedical studies should lead to further understanding of the structure-activity relationships of the Kiss/KissR system.

\section{Supplementary data}

This is linked to the online version of the paper at http://dx.doi.org/10.1530/ JME-13-0224.

Declaration of interest

The authors declare that there is no conflict of interest that could be perceived as prejudicing the impartiality of the review.

\section{Funding}

J P was a recipient of a PhD fellowship from the Ministry of Research and Education. A G L is a researcher in the frame of the European Community program FP7-PROEEL-245257.

\section{Acknowledgements}

The authors gratefully acknowledge Leslie Chevalier for skillful secretarial assistance.

\section{References}

van Aerle R, Kille P, Lange A \& Tyler CR 2008 Evidence for the existence of a functional Kiss1/Kiss1 receptor pathway in fish. Peptides 29 57-64. (doi:10.1016/j.peptides.2007.10.018)

Akazome Y, Kanda S, Okubo K \& Oka Y 2010 Functional and evolutionary insights into vertebrate kisspeptin systems from studies of fish brain. Journal of Fish Biology 76 161-182. (doi:10.1111/j.1095-8649.2009.02496.x)

Arora KK, Krsmanovic LZ, Mores N, O'Farrell H \& Catt KJ 1998 Mediation of cyclic AMP signaling by the first intracellular loop of the gonadotropinreleasing hormone receptor. Journal of Biological Chemistry 273 25581-25586. (doi:10.1074/jbc.273.40.25581) 
Asami T, Nishizawa N, Ishibashi Y, Nishibori K, Nakayama M, Horikoshi Y, Matsumoto S, Yamaguchi M, Matsumoto H, Tarui N et al. 2012 Serum stability of selected decapeptide agonists of KISS1R using pseudopeptides. Bioorganic \& Medicinal Chemistry Letters 22 6391-6396. (doi:10.1016/j.bmcl.2012.08.069)

Baldwin JM 1993 The probable arrangement of the helices in G proteincoupled receptors. EMBO Journal 12 1693-1703.

Becker JA, Mirjolet JF, Bernard J, Burgeon E, Simons MJ, Vassart G, Parmentier M \& Libert F 2005 Activation of GPR54 promotes cell cycle arrest and apoptosis of human tumor cells through a specific transcriptional program not shared by other $\mathrm{G}_{\mathrm{q}}$-coupled receptors. Biochemical and Biophysical Research Communications 326 677-686. (doi:10.1016/j.bbrc.2004.11.094)

Bianco SD, Vandepas L, Correa-Medina M, Gereben B, Mukherjee A, Kuohung W, Carroll R, Teles MG, Latronico AC \& Kaiser UB 2011 KISS1R intracellular trafficking and degradation: effect of the Arg386Pro disease-associated mutation. Endocrinology 152 1616-1626. (doi:10.1210/en.2010-0903)

Biran J, Ben-Dor S \& Levavi-Sivan B 2008 Molecular identification and functional characterization of the kisspeptin/kisspeptin receptor system in lower vertebrates. Biology of Reproduction 79 776-786. (doi:10.1095/biolreprod.107.066266)

Bockaert J \& Pin JP 1999 Molecular tinkering of G protein-coupled receptors: an evolutionary success. EMBO Journal 18 1723-1729. (doi:10.1093/emboj/18.7.1723)

Bourne HR 1997 How receptors talk to trimeric G proteins. Current Opinion in Cell Biology 9 134-142. (doi:10.1016/S0955-0674(97)80054-3)

Cartwright JE \& Williams PJ 2012 Altered placental expression of kisspeptin and its receptor in pre-eclampsia. Journal of Endocrinology 214 79-85. (doi:10.1530/JOE-12-0091)

Castaño JP, Martínez-Fuentes AJ, Gutiérrez-Pascual E, Vaudry H, Tena-Sempere M \& Malagón MM 2009 Intracellular signaling pathways activated by kisspeptins through GPR54: do multiple signals underlie function diversity? Peptides 30 10-15. (doi:10.1016/j.peptides. 2008.07.025)

Castellano JM, Navarro VM, Fernández-Fernández R, Castaño JP, Malagón MM, Aguilar E, Dieguez C, Magni P, Pinilla L \& Tena-Sempere M 2006 Ontogeny and mechanisms of action for the stimulatory effect of kisspeptin on gonadotropin-releasing hormone system of the rat. Molecular and Cellular Endocrinology 257-258 75-83. (doi:10.1016/j.mce.2006.07.002)

Chevrier L, de Brevern A, Hernandez E, Leprince J, Vaudry H, Guedj AM \& de Roux N 2013 PRR repeats in the intracellular domain of KISS1R are important for its export to cell membrane. Molecular Endocrinology $\mathbf{2 7}$ 1004-1014. (doi:10.1210/me.2012-1386)

Chianese R, Ciaramella V, Fasano S, Pierantoni R \& Meccariello R 2013 Kisspeptin receptor, GPR54, as a candidate for the regulation of testicular activity in the frog Rana esculenta. Biology of Reproduction $\mathbf{8 8}$ 73. (doi:10.1095/biolreprod.112.103515)

Choe HK, Kim HD, Park SH, Lee HW, Park JY, Seong JY, Lightman SL, Son GH \& Kim K 2013 Synchronous activation of gonadotropin-releasing hormone gene transcription and secretion by pulsatile kisspeptin stimulation. PNAS 110 5677-5682. (doi:10.1073/pnas.1213594110)

Clements MK, McDonald TP, Wang R, Xie G, O'Dowd BF, George SR, Austin CP \& Liu Q 2001 FMRFamide-related neuropeptides are agonists of the orphan G-protein-coupled receptor GPR54. Biochemical and Biophysical Research Communications 284 1189-1193. (doi:10.1006/ bbrc.2001.5098)

Curtis AE, Cooke JH, Baxter JE, Parkinson JR, Bataveljic A, Ghatei MA, Bloom SR \& Murphy KG 2010 A kisspeptin-10 analog with greater in vivo bioactivity than kisspeptin-10. American Journal of Physiology. Endocrinology and Metabolism 298 E296-E303. (doi:10.1152/ajpendo. 00426.2009)

Dungan Lemko HM \& Elias CF 2012 Kiss of the mutant mouse: how genetically altered mice advanced our understanding of kisspeptin's

http://jme.endocrinology-journals.org DOI: 10.1530/JME-13-0224 (c) 2014 Society for Endocrinology Printed in Great Britain role in reproductive physiology. Endocrinology 153 5119-5129. (doi:10.1210/en.2012-1494)

Eipper BA, Stoffers DA \& Mains RE 1992 The biosynthesis of neuropeptides: peptide $\alpha$-amidation. Annual Review of Neuroscience 15 57-85. (doi:10.1146/annurev.ne.15.030192.000421)

Evans BJ, Wang Z, Mobley L, Khosravi D, Fujii N, Navenot JM \& Peiper SC 2008 Physical association of GPR54 C-terminal with protein phosphatase 2A. Biochemical and Biophysical Research Communications 377 1067-1071. (doi:10.1016/j.bbrc.2008.10.108)

Farrens DL, Altenbach C, Yang K, Hubbell WL \& Khorana HG 1996 Requirement of rigid-body motion of transmembrane helices for light activation of rhodopsin. Science 274 768-770. (doi:10.1126/science. 274.5288.768)

Felip A, Zanuy S, Pineda R, Pinilla L, Carrillo M, Tena-Sempere M \& Gómez A 2009 Evidence for two distinct KiSS genes in non-placental vertebrates that encode kisspeptins with different gonadotropin-releasing activities in fish and mammals. Molecular and Cellular Endocrinology 312 61-71. (doi:10.1016/j.mce.2008.11.017)

Fukusumi S, Fujii R \& Hinuma S 2006 Recent advances in mammalian RFamide peptides: the discovery and functional analyses of PrRP, RFRPs and QRFP. Peptides 27 1073-1086. (doi:10.1016/j.peptides.2005.06.031)

Funes S, Hedrick JA, Vassileva G, Markowitz L, Abbondanzo S, Golovko A, Yang S, Monsma FJ \& Gustafson EL 2003 The KiSS-1 receptor GPR54 is essential for the development of the murine reproductive system. Biochemical and Biophysical Research Communications 312 1357-1363. (doi:10.1016/j.bbrc.2003.11.066)

Gopurappilly R, Ogawa S \& Parhar IS 2013 Functional significance of GnRH and kisspeptin, and their cognate receptors in teleost reproduction. Frontiers in Endocrinology 4 24. (doi:10.3389/fendo.2013.00024)

Gurevich VV \& Gurevich EV 2008 GPCR monomers and oligomers: it takes all kinds. Trends in Neurosciences 31 74-81. (doi:10.1016/j.tins.2007.11.007)

Gutiérrez-Pascual E, Martínez-Fuentes A, Pinilla L, Tena-Sempere M, Malagón M \& Castaño J 2007 Direct pituitary effects of kisspeptin: activation of gonadotrophs and somatotrophs and stimulation of luteinising hormone and growth hormone secretion. Journal of Neuroendocrinology 19 521-530. (doi:10.1111/j.1365-2826.2007.01558.x)

Gutiérrez-Pascual E, Leprince J, Martínez-Fuentes AJ, Ségalas-Milazzo I, Pineda R, Roa J, Duran-Prado M, Guilhaudis L, Desperrois E, Lebreton A et al. 2009 In vivo and in vitro structure-activity relationships and structural conformation of Kisspeptin-10-related peptides. Molecular Pharmacology 76 58-67. (doi:10.1124/mol.108.053751)

Hodne K, Weltzien FA, Oka Y \& Okubo K 2013 Expression and putative function of kisspeptins and their receptors during early development in medaka. Endocrinology 154 3437-3446. (doi:10.1210/en.2013-1065)

Holland LZ, Albalat R, Azumi K, Benito-Gutierrez E, Blow MJ, BronnerFRaser M, Brunet F, Butts T, Candiani S, Dishaw LJ et al. 2008 The amphioxus genome illuminates vertebrate origins and cephalochordate biology. Genome Research 18 1100-1111. (doi:10.1101/ gr.073676.107)

Hultqvist G, Ocampo Daza D, Larhammar D \& Kilimann MW 2012 Evolution of the vertebrate paralemmin gene family: ancient origin of gene duplicates suggests distinct functions. PLoS ONE 7 e41850. (doi:10.1371/journal.pone.0041850)

Kim DK, Cho EB, Moon MJ, Park S, Hwang JI, Do Rego JL, Vaudry H \& Seong JY 2012 Molecular coevolution of neuropeptides gonadotropinreleasing hormone and kisspeptin with their cognate $\mathrm{G}$ proteincoupled receptors. Frontiers in Neuroscience 6 3. (doi:10.3889/fnins. 2012.00003)

Kitahashi T, Ogawa S \& Parhar IS 2009 Cloning and expression of kiss2 in the zebrafish and medaka. Endocrinology 150 821-831. (doi:10.3389/ fnins.2012.00003)

Kotani M, Detheux M, Vandenbogaerde A, Communi D, Vanderwinden JM, Le Poul E, Brezillon S, Tyldesley R, Suarez-Huerta N, Vandeput F et al. 2001 The metastasis suppressor gene KiSS-1 encodes kisspeptins, the natural ligands of the orphan G protein-coupled receptor GPR54. Journal of Biological Chemistry 276 34631-34636. (doi:10.1074/jbc.M104847200) 
Lee JH, Miele ME, Hicks DJ, Phillips KK, Trent JM, Weissman BE \& Welch DR 1996 KiSS-1, a novel human malignant melanoma metastasis-suppressor gene. Journal of the National Cancer Institute $\mathbf{8 8}$ 1731-1737. (doi:10.1093/jnci/88.23.1731)

Lee DK, Nguyen T, O'Neill GP, Cheng R, Liu Y, Howard AD, Coulombe N, Tan CP, Tang-Nguyen AT, George SR et al. 1999 Discovery of a receptor related to the galanin receptors. FEBS Letters 446 103-107. (doi:10.1016/S0014-5793(99)00009-5)

Lee JY, Moon JS, Eu YJ, Lee CW, Yang ST, Lee SK, Jung HH, Kim HH, Rhim H, Seong JY et al. 2009a Molecular interaction between kisspeptin decapeptide analogs and a lipid membrane. Archives of Biochemistry and Biophysics 485 109-114. (doi:10.1016/j.abb.2009.03.002)

Lee YR, Tsunekawa K, Moon MJ, Um HN, Hwang JI, Osugi T, Otaki N, Sunakawa Y, Kim K, Vaudry H et al. 2009b Molecular evolution of multiple forms of kisspeptins and GPR54 receptors in vertebrates. Endocrinology 150 2837-2846. (doi:10.1210/en.2008-1679)

Li S, Zhang Y, Liu Y, Huang X, Huang W, Lu D, Zhu P, Shi Y, Cheng CH, Liu X et al. 2009 Structural and functional multiplicity of the kisspeptin/GPR54 system in goldfish (Carassius auratus). Journal of Endocrinology 201 407-418. (doi:10.1677/JOE-09-0016)

Li Y, Xiang Q, Zhang Q, Huang Y \& Su Z 2012 Overview on the recent study of antimicrobial peptides: origins, functions, relative mechanisms and application. Peptides 37 207-215. (doi:10.1016/j.peptides.2012.07.001)

Liu Z, Ren C, Jones W, Chen P, Seminara SB, Chan YM, Smith NF, Covey JM, Wang J \& Chan KK 2013 LC-MS/MS quantification of a neuropeptide fragment kisspeptin-10 (NSC 741805) and characterization of its decomposition product and pharmacokinetics in rats. Journal of Chromatography. B. Analytical Technologies in the Biomedical and Life Sciences 926 1-8. (doi:10.1016/j.jchromb.2013.02.027)

Luque RM, Córdoba-Chacón J, Gahete MD, Navarro VM, Tena-Sempere M, Kineman RD \& Castaño JP 2011 Kisspeptin regulates gonadotroph and somatotroph function in nonhuman primate pituitary via common and distinct signaling mechanisms. Endocrinology 152 957-966. (doi:10.1210/en.2010-1142)

Masui TD, Doi R, Mori R, Toyoda E, Koizumi M, Kami K, Ito D, Peiper SC, Broach JR, Oishi S et al. 2004 Metastin and its variant forms suppress migration of pancreatic cancer cells. Biochemical and Biophysical Research Communications 315 85-92. (doi:10.1016/j.bbrc.2004.01.021)

Mechaly AS, Viñas J \& Piferrer F 2009 Identification of two isoforms of the Kisspeptin-1 receptor (kiss1r) generated by alternative splicing in a modern teleost, the Senegalese sole (Solea senegalensis). Biology of Reproduction 80 60-69. (doi:10.1095/biolreprod.108.072173)

Mechaly AS, Viñas J \& Piferrer F 2011 Gene structure analysis of kisspeptin-2 (Kiss2) in the Senegalese sole (Solea senegalensis): characterization of two splice variants of Kiss2, and novel evidence for metabolic regulation of kisspeptin signaling in non-mammalian species. Molecular and Cellular Endocrinology 339 14-24. (doi:10.1016/j.mce.2011.03.004)

Michelsen K, Yuan H \& Schwappach B 2005 Hide and run. Arginine-based endoplasmic-reticulum-sorting motifs in the assembly of heteromultimeric membrane proteins. EMBO Reports 6 717-722. (doi:10.1038/ si.embor.7400480)

Mirabeau O \& Joly JS 2013 Molecular evolution of peptidergic signaling systems in bilaterians. PNAS 110 E2028-E2037. (doi:10.1073/ pnas.1219956110)

Misu R, Oishi S, Setsuda S, Noguchi T, Kaneda M, Ohno H, Evans B, Navenot JM, Peiper SC \& Fujii N 2013 Characterization of the receptor binding residues of kisspeptins by positional scanning using peptide photoaffinity probes. Bioorganic \& Medicinal Chemistry Letters 23 2628-2631. (doi:10.1016/j.bmcl.2013.02.098)

Moon JS, Lee YR, Oh DY, Hwang JI, Lee JY, Kim JI, Vaudry H, Kwon HB \& Seong JY 2009 Molecular cloning of the bullfrog kisspeptin receptor GPR54 with high sensitivity to Xenopus kisspeptin. Peptides 30 171-179. (doi:10.1016/j.peptides.2008.04.015)

Muir AI, Chamberlain L, Elshourbagy NA, Michalovich D, Moore DJ, Calamari A, Szekeres PG, Sarau HM, Chambers JK, Murdock P et al. 2001 AXOR12, a novel human $G$ protein-coupled receptor, activated by the peptide KiSS-1. Journal of Biological Chemistry 276 28969-28975. (doi:10.1074/jbc.M102743200)

Nakatani Y, Takeda H, Kohara Y \& Morishita S 2007 Reconstruction of the vertebrate ancestral genome reveals dynamic genome reorganization in early vertebrates. Genome Research 17 1254-1265. (doi:10.1101/gr.6316407)

Niida A, Wang Z, Tomita K, Oishi S, Tamamura H, Otaka A, Navenot JM, Broach JR, Peiper SC \& Fujii N 2006 Design and synthesis of downsized metastin (45-54) analogs with maintenance of high GPR54 agonistic activity. Bioorganic \& Medicinal Chemistry Letters 16 134-137. (doi:10.1016/j.bmcl.2005.09.054)

Nocillado JN, Biran J, Lee YY, Levavi-Sivan B, Mechaly AS, Zohar Y \& Elizur A 2012 The Kiss2 receptor (Kiss2r) gene in Southern Bluefin Tuna, Thunnus maccoyii and in Yellowtail Kingfish, Seriola lalandi - functional analysis and isolation of transcript variants. Molecular and Cellular Endocrinology 362 211-220. (doi:10.1016/j.mce.2012.06.024)

Novaira HJ, Ng Y, Wolfe A \& Radovick S 2009 Kisspeptin increases GnRH mRNA expression and secretion in GnRH secreting neuronal cell lines. Molecular and Cellular Endocrinology 311 126-134. (doi:10.1016/j.mce. 2009.06.011)

Ohga H, Fujinaga Y, Selvaraj S, Kitano H, Nyuji M, Yamaguchi A \& Matsuyama M 2013 Identification, characterization, and expression profiles of two subtypes of kisspeptin receptors in a scombroid fish (chub mackerel). General and Comparative Endocrinology 193C 130-140. (doi:10.1016/j.ygcen.2013.07.016)

Ohtaki T, Shintani Y, Honda S, Matsumoto H, Hori A, Kanehashi K, Terao Y, Kumano S, Takatsu Y, Masuda Y et al. 2001 Metastasis suppressor gene KiSS-1 encodes peptide ligand of a G-protein-coupled receptor. Nature 411 613-617. (doi:10.1038/35079135)

Onuma TA \& Duan C 2012 Duplicated Kiss1 receptor genes in zebrafish: distinct gene expression patterns, different ligand selectivity, and a novel nuclear isoform with transactivating activity. FASEB Journal 26 2941-2950. (doi:10.1096/fj.11-201095)

Orsini MJ, Klein MA, Beavers MP, Connolly PJ, Middleton SA \& Mayo KH 2007 Metastin (KiSS-1) mimetics identified from peptide structureactivity relationship-derived pharmacophores and directed small molecule database screening. Journal of Medicinal Chemistry $\mathbf{5 0} 462-471$. (doi:10.1021/jm0609824)

Osugi T, Ohtaki N, Sunakawa Y, Son YL, Ohkubo M, Iigo M, Amano M \& Tsutsui K 2013 Molecular evolution of Kiss2 genes and peptides in vertebrates. Endocrinology 154 4270-4280. (doi:10.1210/en.2012-2267)

Palczewski K, Kumasaka T, Hori T, Behnke CA, Motoshima H, Fox BA, Le Trong I, Teller DC, Okada T, Stenkamp RE et al. 2000 Crystal structure of rhodopsin: a $\mathrm{G}$ protein-coupled receptor. Science $\mathbf{2 8 9}$ 739-745. (doi:10.1126/science.289.5480.739)

Pasquier J, Lafont AG, Jeng SR, Morini M, Dirks R, van den Thillart G, Tomkiewicz J, Tostivint H, Chang CF, Rousseau K et al. 2012a Multiple kisspeptin receptors in early osteichthyans provide new insights into the evolution of this receptor family. PLoS ONE 7 e48931. (doi:10.1371/ journal.pone.0048931)

Pasquier J, Lafont AG, Tostivint H, Vaudry H, Rousseau K \& Dufour S $2012 b$ Comparative evolutionary histories of kisspeptins and kisspeptin receptors in vertebrates reveal both parallel and divergent features. Frontiers in Endocrinology 3 173. (doi:10.3389/fendo.2012.00173)

Pasquier J, Lafont A-G, Rousseau K, Querat B, Chemineau P \& Dufour S 2014 Looking for the bird Kiss: evolutionary scenario in sauropsids. BMC Evolutionary Biology 14 30. (doi:10.1186/1471-2148-14-30)

Pellissier LP, Barthet G, Gaven F, Cassier E, Trinquet E, Pin JP, Marin P, Dumuis A, Bockaert J, Banères JL et al. $2011 \mathrm{G}$ protein activation by serotonin type 4 receptor dimers: evidence that turning on two protomers is more efficient. Journal of Biological Chemistry 286 9985-9997. (doi:10.1074/jbc.M110.201939)

Pinilla L, Aguilar E, Dieguez C, Millar RP \& Tena-Sempere M 2012 Kisspeptins and reproduction: physiological roles and regulatory mechanisms. Physiological Reviews 92 1235-1316. (doi:10.1152/physrev.00037.2010)

Price DA \& Greenberg MJ $1977 a$ Purification and characterization of a cardioexcitatory neuropeptide from the central ganglia of a bivalve

Published by Bioscientifica Ltd 
mollusc. Preparative Biochemistry 7 261-281. (doi:10.1080/ $00327487708061643)$

Price DA \& Greenberg MJ 1977b Structure of a molluscan cardioexcitatory neuropeptide. Science 197 670-671. (doi:10.1126/science.877582)

Putnam NH, Butts T, Ferrier DE, Furlong RF, Hellsten U, Kawashima T, Robinson-Rechavi M, Shoguchi E, Terry A, Yu JK et al. 2008 The amphioxus genome and the evolution of the chordate karyotype. Nature 453 1064-1071. (doi:10.1038/nature06967)

Ringel MD, Hardy E, Bernet VJ, Burch HB, Schuppert F, Burman KD \& Saji M 2002 Metastin receptor is overexpressed in papillary thyroid cancer and activates MAP kinase in thyroid cancer cells. Journal of Clinical Endocrinology and Metabolism 87 2399. (doi:10.1210/jcem.87.5.8626)

Roa J, Aguilar E, Dieguez C, Pinilla L \& Tena-Sempere M 2008 New frontiers in kisspeptin/GPR54 physiology as fundamental gatekeepers of reproductive function. Frontiers in Neuroendocrinology 29 48-69. (doi:10.1016/j.yfrne.2007.07.002)

de Roux N, Genin E, Carel JC, Matsuda F, Chaussain JL \& Milgrom E 2003 Hypogonadotropic hypogonadism due to loss of function of the KiSS1derived peptide receptor GPR54. PNAS 100 10972-10976. (doi:10. 1073/pnas.1834399100)

Roy A, Kucukural A \& Zhang Y 2010 I-TASSER: a unified platform for automated protein structure and function prediction. Nature Protocols 5 725-738. (doi:10.1038/nprot.2010.5)

Saksela K \& Permi P 2012 SH3 domain ligand binding: what's the consensus and where's the specificity? FEBS Letters 586 2609-2614. (doi:10.1016/ j.febslet.2012.04.042)

Scheer A, Fanelli F, Costa T, De Benedetti PG \& Cotecchia S 1996 Constitutively active mutants of the $\alpha 1 \mathrm{~B}$-adrenergic receptor: role of highly conserved polar amino acids in receptor activation. EMBO Journal 15 3566-3578.

Selvaraj S, Kitano H, Fujinaga Y, Ohga H, Yoneda M, Yamaguchi A, Shimizu A \& Matsuyama M 2010 Molecular characterization, tissue distribution, and mRNA expression profiles of two Kiss genes in the adult male and female chub mackerel (Scomber japonicus) during different gonadal stages. General and Comparative Endocrinology 169 28-38. (doi:10.1016/j.ygcen.2010.07.011)

Seminara SB, Messager S, Chatzidaki EE, Thresher RR, Acierno JS, Shagoury JK, Bo-Abbas Y, Kuohung W, Schwinof KM, Hendrick AG et al. 2003 The GPR54 gene as a regulator of puberty. New England Journal of Medicine 349 1614-1627. (doi:10.1056/NEJMoa035322)

Semple RK, Achermann JC, Ellery J, Farooqi IS, Karet FE, Stanhope RG, O'rahilly S \& Aparicio SA 2005 Two novel missense mutations in g protein-coupled receptor 54 in a patient with hypogonadotropic hypogonadism. Journal of Clinical Endocrinology and Metabolism 90 1849-1855. (doi:10.1210/jc.2004-1418)

Servili A, Le Page Y, Leprince J, Caraty A, Escobar S, Parhar IS, Seong JY, Vaudry H \& Kah O 2011 Organization of two independent kisspeptin systems delivered from evolutionary-ancient kiss genes in the brain of zebrafish. Endocrinology 152 1527-1540. (doi:10.1210/en.2010-0948)

Shi Y, Zhang Y, Li S, Liu Q, Lu D, Liu M, Meng Z, Cheng CH, Liu X \& Lin H 2010 Molecular identification of the Kiss2/Kiss1ra system and its potential function during $17 \alpha$-methyltestosterone-induced sex reversal in the orange-spotted grouper, Epinephelus coioides. Biology of Reproduction 83 63-74. (doi:10.1095/biolreprod.109.080044)

Stafford LJ, Xia C, Ma W, Cai Y \& Liu M 2002 Identification and characterization of mouse metastasis-suppressor KiSS1 and its G-protein-coupled receptor. Cancer Research 62 5399-5404.

Stathatos N, Bourdeau I, Espinosa AV, Saji M, Vasko VV, Burman KD, Stratakis CA \& Ringel MD 2005 KiSS-1/G protein-coupled receptor 54 metastasis suppressor pathway increases myocyte-enriched calcineurin interacting protein 1 expression and chronically inhibits calcineurin activity. Journal of Clinical Endocrinology and Metabolism 90 5432-5440. (doi:10.1210/jc.2005-0963)

Teles MG, Bianco SD, Brito VN, Trarbach EB, Kuohung W, Xu S, Seminara SB, Mendonca BB, Kaiser UB \& Latronico AC 2008 A GPR54-activating mutation in a patient with central precocious puberty. New England Journal of Medicine 358 709-715. (doi:10.1056/ NEJMoa073443)

Tena-Sempere M, Felip A, Gomez A, Zanuy S \& Carrillo M 2012 Comparative insights of the kisspeptin/kisspeptin receptor system: lessons from non-mammalian vertebrates. General and Comparative Endocrinology 175 234-243. (doi:10.1016/j.ygcen.2011.11.015)

Tenenbaum-Rakover Y, Commenges-Ducos M, Iovane A, Aumas C, Admoni O \& de Roux N 2007 Neuroendocrine phenotype analysis in five patients with isolated hypogonadotropic hypogonadism due to a L102P inactivating mutation of GPR54. Journal of Clinical Endocrinology and Metabolism 92 1137-1144. (doi:10.1210/jc.2006-2147)

Tomikawa J, Homma T, Tajima S, Shibata T, Inamoto Y, Takase K, Inoue N, Ohkura S, Uenoyama Y, Maeda K et al. 2010 Molecular characterization and estrogen regulation of hypothalamic KISS1 gene in the pig. Biology of Reproduction 82 313-319. (doi:10.1095/biolreprod.109.079863)

Tomikawa J, Uenoyama Y, Ozawa M, Fukanuma T, Takase K, Goto T, Abe H, Ieda N, Minabe S, Deura C et al. 2012 Epigenetic regulation of Kiss1 gene expression mediating estrogen-positive feedback action in the mouse brain. PNAS 109 E1294-E1301. (doi:10.1073/pnas.1114245109)

Tomita K, Niida A, Oishi S, Ohno H, Cluzeau J, Navenot JM, Wang ZX, Peiper SC \& Fujii N 2006 Structure-activity relationship study on small peptidic GPR54 agonists. Bioorganic \& Medicinal Chemistry 14 7595-7603. (doi:10.1016/j.bmc.2006.07.009)

Topaloglu AK, Tello JA, Kotan LD, Ozbek MN, Yilmaz MB, Erdogan S, Gurbuz F, Temiz F, Millar RP \& Yuksel B 2012 Inactivating KISS1 mutation and hypogonadotropic hypogonadism. New England Journal of Medicine 366 629-635. (doi:10.1056/NEJMoa1111184)

Tsutsui K, Bentley GE, Kriegsfeld LJ, Osugi T, Seong JY \& Vaudry H 2010 Discovery and evolutionary history of gonadotrophin-inhibitory hormone and kisspeptin: new key neuropeptides controlling reproduction. Journal of Neuroendocrinology 22 716-727. (doi:10.1111/j.13652826.2010.02018.x)

Unger VM, Hargrave PA, Baldwin JM \& Schertler GF 1997 Arrangement of rhodopsin transmembrane $\alpha$-helices. Nature 389 203-206. (doi:10.1038/38316)

Vilardaga JP, Agnati LF, Fuxe K \& Ciruela F 2010 G-protein-coupled receptor heteromer dynamics. Journal of Cell Science $\mathbf{1 2 3} 4215-4220$. (doi:10.1242/jcs.063354)

Wacker JL, Feller DB, Tang XB, Defino MC, Namkung Y, Lyssand JS, Mhyre AJ, Tan X, Jensen JB \& Hague C 2008 Disease-causing mutation in GPR54 reveals the importance of the second intracellular loop for class A G-protein-coupled receptor function. Journal of Biological Chemistry 283 31068-31078. (doi:10.1074/jbc.M805251200)

Wahab F, Quinton R \& Seminara SB 2011 The kisspeptin signaling pathway and its role in human isolated GnRH deficiency. Molecular and Cellular Endocrinology 346 29-36. (doi:10.1016/j.mce.2011.05.043)

Witham EA, Meadows JD, Hoffmann HM, Shojaei S, Coss D, Kauffman AS \& Mellon PL 2013 Kisspeptin regulates gonadotropin genes via immediate early gene induction in pituitary gonadotropes. Molecular Endocrinology 27 1283-1294. (doi:10.1210/me.2012-1405)

Zmora N, Stubblefield J, Zulperi Z, Biran J, Levavi-Sivan B, Muñoz-Cueto JA \& Zohar Y 2012 Differential and gonad stage-dependent roles of kisspeptin1 and kisspeptin2 in reproduction in the modern teleosts, Morone species. Biology of Reproduction 86 177. (doi:10.1095/biolreprod.111.097667)

Received in final form 7 February 2014

Accepted 25 February 2014

Accepted Preprint published online 27 February 2014 http://jme.endocrinology-journals.org DOI: 10.1530/JME-13-0224
(C) 2014 Society for Endocrinology Printed in Great Britain
Published by Bioscientifica Ltd 